\title{
Revisão do gênero Willistoniella Mik, 1895 (Diptera, Ropalomeridae) da Região Neotropical
}

\author{
Ana Paula Coelho Marques ${ }^{1,2} \&$ Rosaly Ale-Rocha ${ }^{2}$
}

\begin{abstract}
${ }^{1}$ Departamento de Zoologia, Pós-Graduação em Entomologia, Universidade Federal do Paraná-UFPR. Caixa Postal 19020, $81531-980$ CuritibaPR, Brasil. apcm@ufpr.br.

${ }^{2}$ Coordenação de Pesquisas em Entomologia, Instituto Nacional de Pesquisas da Amazônia-INPA. Caixa Postal 478, 69011-970 Manaus-AM, Brasil. alerocha@inpa.gov.br.
\end{abstract}

\begin{abstract}
Revision of the genus Willistoniella Mik, 1895 (Diptera, Ropalomeridae) of the Neotropical Region. The genus Willistoniella and the type-species W. pleuropunctata (Wiedemann, 1824), are redescribed. Three new species, $W$. latiforceps sp. nov., W. spatulata sp. nov. and W. ulyssesi sp. nov., are described from Brazil (Amazonas). The four species are illustrated and keyed.
\end{abstract}

KEYWORDS. Distribution; identification key; new species; taxonomy; Willistoniella.

RESUMO. Revisão do gênero Willistoniella Mik, 1895 (Diptera, Ropalomeridae) da Região Neotropical. O gênero Willistoniella e a espécie-tipo W. pleuropunctata (Wiedemann, 1824), são redescritos. Três espécies novas, W. latiforceps sp. nov., W. spatulata sp. nov. e W. ulyssesi sp. nov., são descritas do Brasil (Amazonas). As quatro espécies são ilustradas e uma chave para espécies de Willistoniella é fornecida.

PALAVRAS-CHAVE. Chave de identificação; distribuição; espécies novas; taxonomia; Willistoniella.

A família Ropalomeridae compreende, atualmente, 26 espécies distribuídas em oito gêneros (Steyskal 1967; RamírezGarcía \& Hernández-Ortiz 1994). É principalmente neotropical, ocorrendo desde o Sul dos Estados Unidos da América até o Norte da Argentina, com uma única espécie conhecida na Região Neártica, Rhytidops floridensis (Aldrich, 1932) (Steyskal 1987). No Brasil foram registradas 21 espécies em seis gêneros (Steyskal 1967; Prado \& Papavero 2002).

Willistoniella Mik, 1895 é um gênero de moscas castanhas, medindo de 7 a $11 \mathrm{~mm}$, fronte ampla e pouco côncava, face carenada medianamente, arista plumosa, pleura com pontuações de polinosidade dourada, escutelo geralmente com 1 par de cerdas apical e 1 par marginal destacados e pernas com fêmures pouco engrossados.

É o gênero de Ropalomeridae mais abundantemente coletado, constituindo frequentemente mais de $50 \%$ dos exemplares encontrados nas coleções. O gênero é monotípico, incluindo apenas a espécie Willistoniella pleuropunctata (Wiedemann, 1824), com ampla distribuição, do Sul do México ao norte da Argentina (Steyskal, 1967).

Este trabalho inclui, além da redescrição de $W$. pleuropunctata, a descrição de $W$. latiforceps sp. nov., $W$. spatulata sp. nov. e $W$. ulyssesi $\mathbf{s p . ~ n o v . ~} W$. pleuropuncata teve seu registro confirmado para o México, Panamá, Trinidade, Venezuela, Peru, Bolívia, Paraguai e Brasil (Roraima, Amazonas, Pará, Rondônia, Mato Grosso, Espírito Santo, Rio de Janeiro, São Paulo e Santa Catarina) e foi registrada pela primeira vez em Tocantins, Sergipe, Maranhão, Distrito Federal, Goiás e Minas Gerais.

\section{MATERIAL E MÉTODOS}

Para este estudo, foram examinados 812 espécimes montados em alfinetes. $\mathrm{O}$ abdome foi desprendido, para análise das estruturas da terminália. A terminália masculina foi aquecida em ácido láctico $85 \%$, por 15-30 minutos em média. A terminália feminina, por ser mais frágil, permaneceu em solução de hidróxido de potássio $10 \%$ a frio durante cerca de $24-48$ horas. Posteriormente, foi colocada em solução de ácido acético e lavada em água destilada. As peças foram acondicionadas em microtubos de plástico $(4 \times 10 \mathrm{~mm})$, com glicerina, e afixados no alfinete do espécime. A asa foi destacada e mergulhada em xilol por algumas horas sendo, posteriormente, montada com bálsamo do Canadá, entre lamínulas e fotografada.

A terminologia empregada segue o trabalho de McAlpine (1981).

As abreviaturas citadas no texto correspondem as seguintes instituições responsáveis pelo empréstimo do material: FMNH, "Field Museum of Natural History", Chicago; INPA, Instituto Nacional de Pesquisas da Amazônia, Manaus; MCZ, "Museum of Comparative Zoology", Cambridge; MPEG, Museu Paraense Emílio Goeldi, Belém; MZSP, Museu de Zoologia da Universidade de São Paulo, São Paulo; NHMW, "Naturhistorisches Museum Wien", Viena; USNM, "National Museum of Natural History", Washington, D. C.

\section{Willistoniella Mik, 1895}

Rhopalomyia Williston, 1895: 184 (pré-ocupado, Rübsaamen, 1892). Espécie-tipo: Ropalomera pleuropunctata Wiedemann, 1824. 
Willistoniella Mik, 1895: 136 (nome novo para Rhopalomyia Williston); Williston, 1896: 280-281 (chave); Lindner, 1930a: 125-129 (diagnose, chave, redescrição); Malloch, 1941: 50 (diagnose); Frey, 1959: 47 (citação); Prado, 1963: 466 (diagnose); 1966: 213, 247 (chave, diagnose); Steyskal, 1987: 85 (chave); Ramírez-García e Hernández-Ortíz, 1994: 72 (diagnose); Prado \& Papavero, 2002: 2 (catálogo).

Espécie-tipo: Ropalomera pleuropunctata Wiedemann, 1824 (designação original).

Diagnose. Fronte ampla, pouco côncava, projetada anteriormente; 2 pares de cerdas orbitais; ocelares, pósocelares, verticais interna e externa presentes; arista plumosa, com pêlos esparsos; face carenada medianamente; pleura com pequenos pontos de polinosidade dourada no anepisterno; escutelo com extremidade arredondada, um par de cerdas marginais e um par apical; 6 ou mais cerdas na borda superior do espiráculo metatorácico; fêmures pouco engrossados em relação aos outros gêneros.

Descrição (macho e fêmea). Cabeça: fronte ampla, pouco côncava, projetada anteriormente; faixa estreita de polinosidade prateada no meio da fronte, nas órbitas oculares, no triângulo ocelar e no esclerito occipital mediano; 2 pares de cerdas orbitais presentes; ocelar, pós-ocelar, verticais interna e externa presentes; uma fileira de cerdas pós-oculares; face com carena mediana central; pedicelo com 1 cerda distinta na margem dorsal; arista plumosa, a metade basal amarelada com pêlos longos, o restante castanho e nu; gena estriada, com uma faixa longitudinal de polinosidade prateada que estendese até a região pós-ocelar; uma fileira de cerdas fortes no esclerito parafacial, próximo à sutura genofacial; gena e pósgena cerdosas.

Tórax: escuto com faixas de polinosidade dourada e/ou prateada, cerdas de revestimento curtas e várias cerdas destacadas. Escutelo com extremidade arredondada, região discal plana e nua (Figs. 1,9). Sub-escutelo com ou sem faixa de polinosidade dourada. Pleura com cerdas de revestimento curtas no anepisterno, pontos de inserção das cerdas cercados por polinosidade dourada; 1 cerda anepisternal destacada e 1 catepisternal; anepímero sem cerdas destacadas; 6 ou mais cerdas na borda superior do espiráculo metatorácico.

Asa: tégula com 3-6 cerdas destacadas; semi-hialina com tonalidade amarelada desprovida de manchas distintas; $1 / 3$ basal da $\mathrm{r}_{1}$ hialino; ${ }^{2}{ }_{3}$ distais da $\mathrm{r}_{1}$, sc e parte da $\mathrm{r}_{2+3}$ amarelo mais escuro que o restante da asa; $\mathrm{R}_{4+5}$ sinuosa, côncava distalmente; distância entre a forquilha do setor radial e o final da Sc curta; última seção da M convexa na metade basal; $\mathrm{CuA}_{2}$ reta (Figs. 48-51).

Pernas: fêmures pouco engrossados em relação aos outros gêneros da família, todos com 1 cerda basal ventral fina e longa. Tíbia anterior com 1 cerda subapical dorsal destacada. Tíbia média com 1 cerda subapical dorsal destacada e 2-3 cerdas fortes apicais ventrais. Tíbia posterior alargada, achatada lateralmente, com a face dorsal laminar e 4-5 cerdas bem diferenciadas na margem póstero-dorsal (Fig. 10).

Abdome: quadriculado com 4 manchas de polinosidade prateadas nos tergitos 2-5 ( 2 centrais e 2 laterais). Terminália feminina telescopada, membranosa na maior parte; tergito 6 pouco esclerotinizado, com pilosidade esparsa e uma fileira de pequenas cerdas na região póstero-lateral (Figs. 18, 22, 40, 44); segmento 7 parcialmente membranoso; esternito 7 com pequena placa basal com 1 par de cerdas (Figs. 19, 23, 41, 45); tergito 7 reduzido a uma placa basal (Figs. 18, 22, 40, 44); um espiráculo nos segmentos 6 e 7; epiprocto alongado, com 1 par de cerdas destacadas na porção apical; hipoprocto mais curto com fenda mediana longitudinalmente, que não atinge o ápice (Figs. 19, 23, 41, 45); cerco delgado, cerdoso, com cerdas maiores no ápice. Esternito 5 masculino retangular e cerdoso. Terminália masculina: cercos totalmente fusionados, formando uma peça única (Figs. 3-4, 12-13, 27-28, 34-35); parâmero com o lóbulo externo mais cerdoso que o interno e a margem interna apresentando uma expansão lateral membranosa (Figs. 6-8, 15-17, 30-32, 37-39); edeago membranoso em sua maior parte, com o ápice piloso, curvo e dobrado para baixo e uma linha longitudinal esclerotinizada ventral nos $2 / 3$ basais; epifalo em gancho (Figs. 6-7, 15-16, 30-31, 37-38).

Comprimento do corpo. 7,3 mm - 11,5 mm.

Distribuição geográfica. México, Belize, Guatemala, Honduras, Curaçao, Costa Rica, Panamá, Trinidade, Suriname, Guianas, Venezuela, Colômbia, Equador, Peru, Brasil, Bolívia, Paraguai e norte da Argentina.

Comentários. Distingue-se facilmente dos outros gêneros de Ropalomeridae pela presença de uma carena mediana na face, enquanto que todos os demais gêneros possuem um tubérculo hemisférico central. Além disso, todas as espécies possuem um padrão de polinosidade abdominal característico: abdome quadriculado com 4 manchas de polinosidade prateadas nos tergitos 2-5. As espécies deste gênero assemelham-se muito entre si, sendo de difícil separação, quando considera-se apenas a morfologia externa. Podem, entretanto, ser facilmente separadas pela morfologia das terminálias feminina e, principalmente, masculina. Na maioria das vezes, é necessária a dissecção para observação destas estruturas. Entretanto, se os espécimes (principalmente machos) forem montados e secados de forma que seja possível a visualização dos surstilos, a dissecção torna-se desnecessária. Às vezes, quando a fêmea é montada com o ovipositor distendido, também é possível identificar-se algumas espécies sem a dissecção.

Chave para as espécies de Willistoniella Mik, 1895 (macho e fềmea)

1. Tergito 7 da fêmea com uma reentrância na extremidade posterior, em forma de U invertido (Fig. 44); esternito 7 da fêmea com uma placa sub-basal grande com cerca de 4 saliências consecutivas, formando pequenas ondulações (Figs. 45-46); esternito 5 do macho largo, com 1 cerda longa nos ângulos póstero-laterais (Fig. 33); surstilo longo, ultrapassando a margem posterior do epândrio (Figs. 34-35)

Willistoniella ulyssesi sp. nov. 
Tergito 7 da fêmea com uma reentrância na extremidade posterior, em forma de V (Figs. 18, 22, 40); esternito 7 da fêmea com uma placa sub-basal longitudinal reduzida ou ausente (Figs. 19, 23, 41); esternito 5 do macho com 1 a 3 cerdas longas nos ângulos pósterolaterais (Figs. 2, 11, 26); surstilo curto, não ultrapassando a margem posterior do epândrio (Figs. $3-4,12-13,27-28)$

2(1). Esternito 7 da fêmea sem placa sub-basal longitudinal (Fig. 41); esternito 5 do macho com 2 cerdas longas nos ângulos póstero-laterais (Fig. 26); surstilo fino com a porção apical mais alargada, arredondada e cerdosa, lembrando a forma de uma espátula (Figs. 2729) ............................. Willistoniella spatulata sp. nov.

Esternito 7 da fêmea com 1-2 placas sub-basais longitudinais (Figs. 19, 23); esternito 5 do macho com 2-3 cerdas longas nos ângulos póstero-laterais (Figs. 2,11 ); surstilo não como acima

3(2). Esternito 7 da fêmea com 1 placa sub-basal longitudinal curta (Fig. 19); esternito 5 do macho com 2 cerdas longas nos ângulos póstero-laterais e uma fileira de 4 cerdas menores nas margens laterais (Fig. 2); surstilo largo, com ápice truncado (Figs. 3-5)

Willistoniella latiforceps sp. nov.

Esternito 7 da fêmea quase imperceptível, com 2 placas sub-basais longitudinais, paralelas, estreitas e pouco esclerotinizadas (Fig. 23); esternito 5 do macho com 3 cerdas longas nos ângulos póstero-laterais (Fig. 11); surstilo delgado, com ápice afilado (Figs. 12-14) ........ Willistoniella pleuropunctata(Wiedemann)

\section{Willistoniella latiforceps sp. nov.}

(Figs. 1-8, 18-21, 48)

Diagnose. Face esbranquiçada, amarelada ou ferrugem com manchas castanhas no ápice da carena e nas extremidades látero-basais, ou somente nestas últimas; terminália feminina: tergito 7 com uma reentrância na extremidade posterior em forma de $\mathrm{V}$; esternito 7 composto por uma pequena placa basal transversal com um par de cerdas e uma placa sub-basal curta longitudinal; esternito 5 do macho com 2 cerdas mais longas nos ângulos póstero-laterais e uma fileira de 4 cerdas menores nas margens laterais; terminália masculina: surstilo alargado, com ápice truncado.

Holótipo macho. Comprimento do corpo: 11,4 mm. Comprimento e largura da asa: 8,3 $\mathrm{mm}$ x 2,7 mm.

Cabeça: fronte castanho-escura; cerca de 9 cerdas pósoculares; face esbranquiçada, com manchas castanhas no ápice da carena e nas extremidades látero-basais; artículos antenais, clípeo, palpo, gena e pós-gena castanho-escuros; gena e pós-gena com cerdas ruivas; 7 cerdas no esclerito parafacial.

Tórax: escuto castanho-escuro, com as seguintes faixas de polinosidade: 1 acrostical prateada esparsa, estreita e incompleta, limitando-se à região pré-sutural do escuto; 1 dorsocentral dourada que se estende até o ápice do escutelo e 1 lateral dourada estendendo-se do lóbulo pós-pronotal até o calo pós-alar; cerdas destacadas: 1 pós-pronotal (1 cerda extra mais interna, reduzida, no lado esquerdo), 3 notopleurais (uma delas reduzida), 1 supra-alar pré-sutural reduzida, 1 supraalar pós-sutural, 1 pós-alar, 2 intra-alares (a anterior reduzida), 1 intra-pós-alar, 1 dorsocentral pré-escutelar pós-sutural reduzida e 1 acrostical pré-escutelar pós-sutural. Escutelo castanho-escuro com 1 cerda apical e 1 marginal (Fig. 1). Subescutelo castanho com faixa de polinosidade dourada. Pleura castanho-escura; mais de 8 cerdas na borda superior do espiráculo metatorácico.

Asa (Fig. 48): tégula com 4 a 6 cerdas destacadas (variação no mesmo espécime); medidas das seções da veia Costa: I 1.5 mm, II $2 \mathrm{~mm}$, III $2 \mathrm{~mm}$, IV $1.5 \mathrm{~mm}, \mathrm{~V} 0.7 \mathrm{~mm}$ e VI $0.3 \mathrm{~mm}$.

Pernas: coxas cobertas por polinosidade prateada esparsa, com cerdas negras. Trocânteres castanhos. Todos os fêmures sem polinosidade. Fêmur anterior castanho-escuro, com várias cerdas dorsais desalinhadas; face ventral com uma fileira de 8 cerdas na margem anterior, a mais basal menor, uma fileira de 9 cerdas na margem posterior. Fêmur médio castanho-claro nos $2 / 3$ basais e escuro no restante; face ventral com uma fileira de 15-16 cerdas curtas na margem anterior, a cerda basal mais fraca, uma fileira de 15-16 cerdas na margem posterior. Fêmur posterior castanho-escuro, a parte média da face dorsal castanho-clara; face dorsal com inúmeras cerdas irregularmente distribuídas; face ventral com uma fileira de 12 cerdas curtas na margem anterior e 6-8 na margem posterior, as duas basais menores e mais fracas. Todas as tíbias castanho-escuras; base das tíbias média e posterior com pequena mancha de polinosidade prateada nas faces anterior e posterior; tíbia posterior direita com 5 cerdas na margem póstero-dorsal, a esquerda com 4 cerdas. Tarsômero 1 coberto por polinosidade esbranquiçada dorsal e intensa pilosidade dourada ventral; demais tarsômeros castanho-escuros.

Abdome: castanho-escuro; esternito 5 com 2 cerdas mais longas nos ângulos póstero-laterais, uma fileira de 4 cerdas menores nas margens laterais, a mais basal menor; várias cerdas de tamanhos variáveis uniformemente distribuídas na porção posterior, próximo à região membranosa (Fig. 2); cerco moderadamente cerdoso e longo, com cerdas uniformemente distribuídas nas laterais e no ápice, as do ápice mais longas (Figs. 3-4); surstilo alargado, pouco mais longo que o cerco, não ultrapassando a margem posterior do epândrio, truncado apicalmente (Figs. 3-5); epifalo e parâmero alargados (Figs.68 ); edeago dobrado para baixo no $1 / 3$ distal, cerca de 2 vezes o comprimento do parâmero (Figs. 6-7).

Fêmea. Comprimento do corpo: 9,8 mm. Comprimento e largura da asa: $8,1 \mathrm{~mm}$ x 2,6 mm.

Como no macho, exceto pelo que segue: medidas das seções da veia Costa: I $1.2 \mathrm{~mm}$, II $2 \mathrm{~mm}$, III $2 \mathrm{~mm}$, IV $1.5 \mathrm{~mm}, \mathrm{~V}$ $0.7 \mathrm{~mm}$ e VI $0.3 \mathrm{~mm}$. Terminália: tergito 7 com reentrância em forma de $\mathrm{V}$ na extremidade posterior e uma projeção que se 
estende látero-ventralmente, visível na face ventral (Figs. 1820 ); esternito 7 composto por uma pequena placa basal transversal com um par de cerdas e uma placa sub-basal longitudinal curta (Fig. 19); espermateca oval, alongada, com numerosas estrias transversais (Fig. 21).

\section{Distribuição geográfica. Brasil (Amazonas).}

Material-tipo examinado. Holótipo macho (INPA), etiquetado: BRASIL, Amazonas, P[residente] Figueiredo, AM 240, Km 24, Com[unidade] S. Fco. de Assis, 02 $01^{\prime} S$ 59 $49^{\prime} \mathrm{W}, 01-11 . i x .2002$ (etiqueta impressa branca)/ isca de banana fermentada, F. Xavier \& U. Barbosa leg. (etiqueta impressa branca)/ Holótipo, Willistoniella latiforceps, Marques \& Ale-Rocha (etiqueta impressa vermelha).

Condição do holótipo: em perfeito estado de conservação, não dissecado.

Parátipos. BRASIL, Amazonas, Parque Nacional do Jaú, 1629.vi.2001, arm[adilha] Shannon, J. F. Vidal leg., 1 macho (INPA); Manaus, E[stação] E[xperimental] [de] F[ruticultura] T[ropical], BR174, km 40, 21.iii.[19]97, McPhail [em] araçá-pêra, [B.] RonchiTeles leg., 1 macho (INPA); ibidem, 2.v.[19]97, 1 macho (INPA); ibidem, 1 macho (INPA); ibidem, 17.vii.[19]97, 1 macho (INPA); R[eserva] [Adolpho] Ducke, [26 km NE, 253'S 5959' W], 1924.v.1988, isca de fruta, Y. Câmara \& J. E. Bindá leg., 1 macho (USNM); ibidem, 10-15.vi.1988, 3 machos (INPA); ibidem, 05-12.viii.1988, 1 macho (USNM); ibidem, 27.x-03.xi.1988, 1 macho (INPA); ibidem, 16-19.v.1988, Y. Câmara \& F. Xavier leg., 1 macho (INPA); ibidem, 24-28.vi.1988, 1 macho (INPA); ibidem, 20-27.viii.1988, 1 macho (INPA); Embrapa, AM- 010, Km 31, 29.viii.1990, arm[adilha] Shannon, Isc[a de] Fruta, Capoeira, L. P. Albuquerque \& J. E. Bindá leg., 1 macho (MZSP); ibidem, 30.x.1991, C[ultura de] Guaraná, 1 macho (INPA); ibidem, 29.viii.1990, C[ultura de] Cacau, 1 fêmea (INPA); ibidem, 14.viii.1991, 1 macho (MZSP); ibidem, 18.ix.1990, C[ultura de] Andiroba, 1 fêmea (INPA); Presidente Figueiredo, iv.2001, arm[adilha] McPhail, [B.] Ronchi-Teles leg., 2 machos (INPA); ibidem, 1 macho (FMNH); ibidem, 1 macho (MCZ); Com[unidade] S[ão] F[rancis]co de

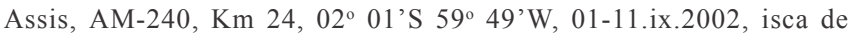
banana fermentada, F. Xavier \& U. Barbosa leg., 3 fêmeas e 2 machos (INPA).

Variações. Fronte castanha; 8-11 cerdas pós-oculares; face com coloração esbranquiçada, amarelada ou ferrugem, com manchas escuras no ápice da carena e nas extremidades láterobasais, ou somente nestas últimas; um exemplar macho apresentou mancha escura no meio da carena; artículos antenais castanhos ou alaranjados; flagelo mais escuro na margem dorsal ou com polinosidade dourada na face interna; gena castanho-clara; 6-9 cerdas no esclerito parafacial, sendo comum variação num mesmo exemplar; escuto com 2-3 cerdas notopleurais e 1-2 pós-pronotais; faixa acrostical de polinosidade prateada ausente; mais de 8 cerdas na borda superior do espiráculo metatorácico; observou-se um exemplar fêmea com 2 supra-alares pós-suturais, a anterior mais reduzida e 1 escutelar extranumerária subapical na metade direita do escutelo. Todos os fêmures inteiramente castanhos; número de cerdas destacadas das pernas variável, mas sempre com o mesmo padrão de distribuição; a maioria dos exemplares com 4 cerdas na margem póstero-dorsal da tíbia posterior.

Comentários. Assemelha-se a W. pleuropunctata, em relação à coloração da face, uma vez que não possui muitas manchas distintas. Entretanto, geralmente a coloração da face é mais clara, esbranquiçada, auxiliando na sua distinção. O aspecto geral é igual ao das demais espécies, diferindo apenas pela terminália de ambos os sexos. O macho apresenta cerco, epifalo e parâmero semelhantes aos de $W$. ulyssesi sp. nov., entretanto o surstilo é bastante alargado, o que a distingue de qualquer outra espécie do gênero. A terminália feminina assemelha-se a de $W$. pleuropunctata, diferindo pela forma do esternito 7, composto por uma pequena placa basal transversal com um par de cerdas e uma placa sub-basal longitudinal curta, bem visíveis, ao contrário do que ocorre em $W$. pleuropunctata.

Etimologia. Do Latim, lati= largo e forceps $=$ fórcepes, referindo-se ao surstilo, que é bem largo em relação aos das outras espécies deste gênero. Faz-se aqui uma referência ao trabalho de Prado (1966), no qual o autor chama os surstilos de "forcipes inferiores".

\section{Willistoniella pleuropunctata (Wiedemann, 1824)} (Figs. 9-17, 22-25, 49)

Ropalomera pleuropunctata Wiedemann, 1824: 18; 1828: 572 (redescrição).

Rhopalomera vittifrons [sic] Rondani, 1848: 81.

Ropalomera substituta [sic] Walker, 1858: 225.

Rhopalomera pleuropunctata; Giglio-Tos, 1894: 43; Frey, 1921: 101103 (redescrição); Aldrich, 1905: 600.

Rhopalomyia pleuropunctata Williston, 1895: 184-186.

Willistoniella pleuropunctata; Hendel, 1923: 203 (citação, distr. geográfica); 1933: 214 (citação, distr. geográfica); Lindner, 1930a: 128-129 (redescrição, distr. geográfica); 1930b: 282 (citação); Aldrich, 1932: 11 (distr. geográfica); Fischer, 1932: 449 (descrição do pupário); Steyskal, 1957: 71 (terminália masculina); 1987: 943 (terminália masculina, identificação errônea $=W$. ulyssesi sp. nov.); Hennig, 1958: 581-590 (ilustrações); Frey, 1959: 47 (citação, distr. geográfica); Prado, 1963: 466-469 (redescrição, ilustrações, identificação errônea $=W$. ulyssesi sp. nov.); 1966: 247 (citação, distr. geográfica); 1967: 73 (citação); Baez, 1985: 80 (citação, distr. geográfica); Ramírez-García \& Hernández-Ortiz, 1994: 7275, 83 (diagnose, distr. geográfica, chave, ilustrações, identificação errônea $=W$. ulyssesi sp. nov.); Prado \& Papavero, 2002: 2 (catálogo).

Diagnose. Face com coloração uniforme variando do amarelo ao castanho-escuro; eventualmente, a carena e as laterais da face apresentam-se avermelhadas; terminália feminina: tergito 7 com reentrância em forma de $\mathrm{V}$ na extremidade posterior; esternito 7 quase imperceptível, com pequena placa basal transversal com um par de cerdas e duas placas sub-basais longitudinais, paralelas, estreitas e pouco esclerotinizadas; esternito 5 do macho com 3 cerdas longas nos ângulos póstero-laterais; terminália masculina: surstilo delgado com ápice afilado.

Holótipo fêmea. Comprimento do corpo: $8 \mathrm{~mm}$. Comprimento e largura da asa: $6,8 \mathrm{~mm} \times 2 \mathrm{~mm}$.

Cabeça: fronte castanha; uma cerda extranumerária curta presente entre as cerdas pós-ocelares; 11 cerdas pós-oculares; face amarelada, margem inferior acastanhada; artículos antenais 

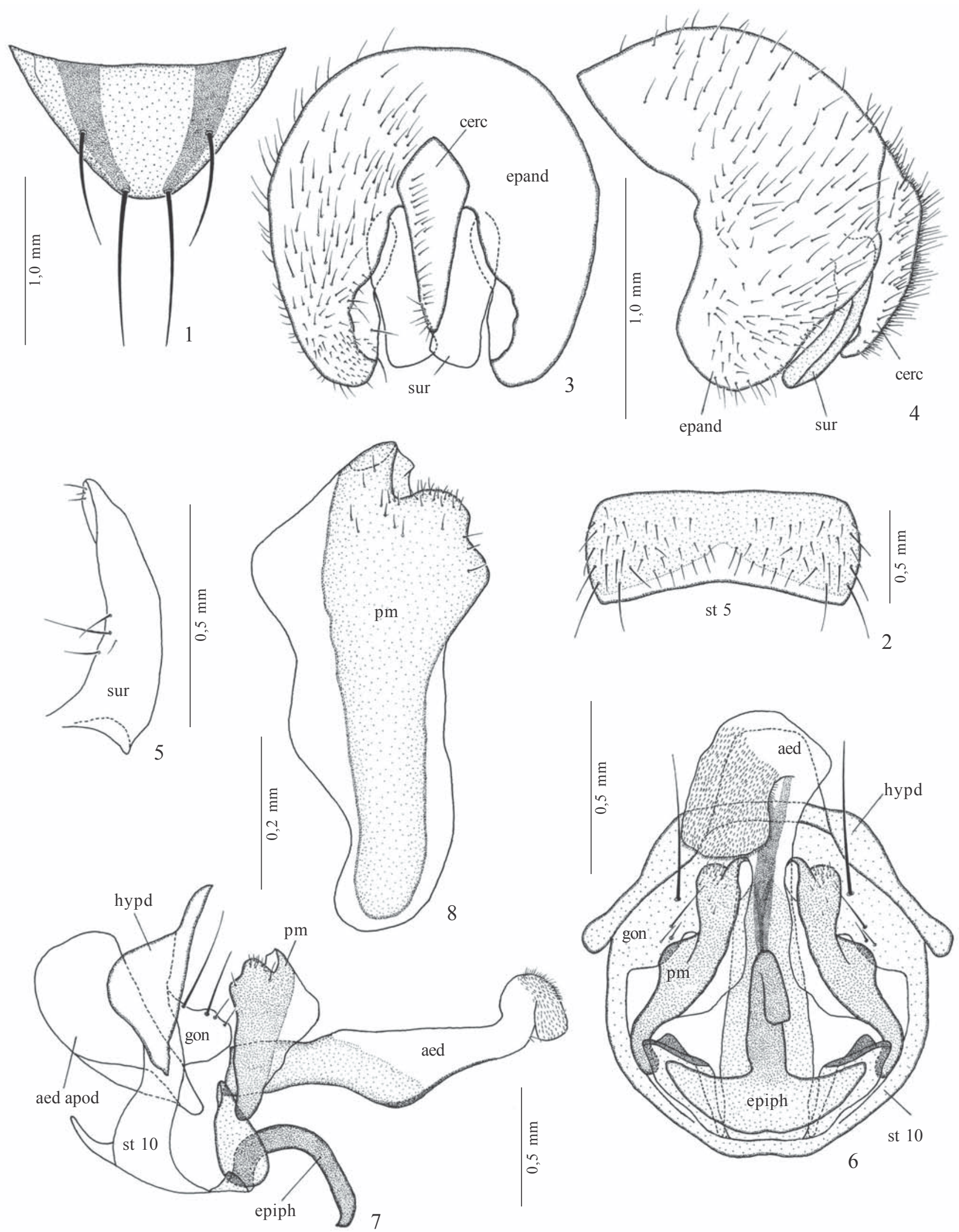

Figs. 1-8. Willistoniella latiforceps sp. nov. (parátipo macho): 1, escutelo; 2, esternito 5 (vista ventral); 3-4, terminália masculina (vista ventral e lateral, mesma escala); 5, surstilo esquerdo (vista lateral); 6-7, terminália masculina interna (vista ventral e lateral); 8, parâmero esquerdo (vista lateral interna); aed = edeago; aed apod = apódema do edeago; cerc $=$ cerco; epand = epândrio; epiph $=$ epifalo; gon = gonópodo; hypd = hipândrio; $\mathrm{pm}=$ parâmero; $\mathrm{st}=$ esternito; sur $=$ surstilo . 
alaranjados; flagelo alaranjado mais escuro na margem dorsal; clípeo castanho; palpo castanho-escuro; gena e pós-gena castanha com cerdas ruivas; 7 cerdas no esclerito parafacial.

Tórax: escuto castanho-escuro, com as seguintes faixas de polinosidade: 1 acrostical prateada esparsa, estreita e incompleta, limitando-se à região pré-sutural do escuto; 1 dorsocentral dourada que se estende até o ápice do escutelo e 1 lateral dourada estendendo-se do lóbulo pós-pronotal até o calo pós-alar; cerdas destacadas: 1 pós-pronotal, 2 notopleurais, 1 supra-alar pós-sutural, 1 pós-alar, 2 intra-alares (a anterior reduzida), 1 intra-pós-alar, 1 dorsocentral préescutelar pós-sutural reduzida, 1 acrostical pós-sutural adiante do escutelo; supra-alar pré-sutural ausente. Escutelo castanhoescuro com 1 cerda apical e 1 marginal de cada lado e 1 cerda extranumerária menor, lateral à cerda marginal, no lado direito (Fig. 9). Subescutelo castanho com faixa de polinosidade dourada. Pleura castanho-escura; 7 cerdas na borda superior do espiráculo metatorácico.

Asa (Fig. 49): tégula com 3 cerdas destacadas; medidas das seções da veia Costa: I $1.2 \mathrm{~mm}$, II $2 \mathrm{~mm}$, III $1.5 \mathrm{~mm}$, IV 1.5 $\mathrm{mm}, \mathrm{V} 0.5 \mathrm{~mm}$ e VI $0.2 \mathrm{~mm}$.

Pernas: coxas com polinosidade prateada esparsa, com cerdas ruivas. Trocânteres castanhos. Todos os fêmures sem polinosidade. Fêmur anterior castanho; fêmur médio e posterior castanho-claros. Fêmur anterior com várias cerdas dorsais distribuídas irregularmente; margem anterior da face ventral com uma fileira de 7 cerdas, sendo a mais basal menor e mais fraca; margem posterior com uma fileira de 8-10 cerdas curtas. Fêmur médio com uma fileira de 14 cerdas curtas na margem anterior da face ventral e uma de 13 cerdas na margem posterior, sendo as 3 cerdas basais mais fracas. Fêmur posterior (Fig. 10) com várias cerdas dorsais distribuídas irregularmente, uma fileira de 11 cerdas curtas no ${ }^{1} / 3$ apical da margem anterior e 5 cerdas na margem posterior da face ventral. Tíbia anterior castanha com anel amarelo na porção média; tíbia média castanha com mancha amarelada nos $2 / 3$ apicais e tíbia posterior castanha com 4 cerdas na margem póstero-dorsal; base das tíbias média e posterior com pequena mancha de polinosidade prateada nas faces anterior e posterior. Tarsômero 1 coberto por polinosidade esbranquiçada dorsal e intensa pilosidade dourada ventral; demais tarsômeros castanho-escuros.

Abdome: castanho-escuro; terminália: tergito 7 com reentrância em forma de $\mathrm{V}$ na extremidade posterior, com projeção que se estende látero-ventralmente, visível na face ventral (Figs. 22-24); esternito 7 quase imperceptível, composto por uma pequena placa basal transversal com um par de cerdas e duas placas sub-basais longitudinais, paralelas, estreitas e pouco esclerotinizadas (Fig. 23); espermateca alongada com numerosas estrias transversais (Fig. 25).

Macho. Comprimento do corpo: 8,0 mm. Comprimento e largura da asa: $6,5 \mathrm{~mm} \times 2,0 \mathrm{~mm}$.

Como na fêmea, exceto pelo que segue: medidas das seções da veia Costa: I $1.2 \mathrm{~mm}$, II $1.5 \mathrm{~mm}$, III $1.3 \mathrm{~mm}$, IV $1 \mathrm{~mm}, \mathrm{~V} 0.5 \mathrm{~mm}$ e VI $0.3 \mathrm{~mm}$. Esternito 5 curto, com 3 cerdas longas nos ângulos póstero-laterais e várias cerdas mais curtas de tamanhos variáveis uniformemente distribuídas na porção posterior, próximo à região membranosa (Fig. 11). Terminália: cerco esparsamente cerdoso, curto, base arredondada com cerdas distribuídas irregularmente nas laterais (Figs. 12-13); surstilo delgado, com ápice afilado, pouco mais longo que o cerco, não ultrapassando a margem posterior do epândrio (Figs. 1214); epifalo e parâmero estreitados (Figs. 15-17); edeago longo, dobrado para baixo no $1 / 3$ distal, cerca de 2,5 vezes o comprimento do parâmero (Figs. 15-16).

Distribuição geográfica. México, Belize, Guatemala, Honduras, Curaçao, Costa Rica, Panamá, Trinidade, Suriname, Guiana, Venezuela, Colômbia, Equador, Peru, Brasil (Roraima, Pará, Amazonas, Tocantis, Rondônia, Sergipe, Maranhão, Bahia, Mato Grosso, Distrito Federal, Goiás, Espírito Santo, Rio de Janeiro, Minas Gerais, São Paulo e Santa Catarina), Bolívia, Paraguai e Argentina.

Material-tipo examinado. Holótipo fêmea (NHMW), etiquetado: "Willistoniella pleuropunctata Wied[emann], det. Lind[ner]"; "pleuropunctata det. Wied[emann]"; "Coll. Winthem"; "Holotype" (etiqueta manuscrita vermelha). Observação: a localidade-tipo é indeterminada, constando, segundo alguns autores (Aldrich, 1932; Steyskal, 1967), apenas como "América do Sul". Entretanto, o holótipo não apresenta nenhuma etiqueta indicando local e data de coleta, estas provavelmente foram perdidas. Porém, sabe-se que Wiedemann, autor da espécie, estudou exemplares provenientes dos seguintes países: Venezuela, Colômbia, Equador, Peru, México e Brasil (Região Amazônica, Ceará, Pernambuco e Bahia), o que confirma que o holótipo seja proveniente da América do Sul (Papavero, 1971).

Condição do holótipo: cerdas ocelares, arista direita e tarsos anteriores de ambas as pernas quebrados; escuto com grande área danificada pelo alfinete; várias cerdas do escuto ausentes; asa direita e pernas média e posterior direitas perdidas; abdome cortado a partir do segmento 4, para dissecção da terminália, acondicionada em tubo com glicerina.

Material examinado. MÉXICO, Colima, Vulcano, [sem data], L. Conrad leg., 1 fêmea (INPA); PANAMÁ, C [anal] Z[one], [Parque Nacional] Barro Colorado, 31.xii.[19]37, "fruit fly trap", n 3797, J. Zetek leg., 1 fêmea (USNM); ibidem, Corozal, [sem data], 1 fêmea (USNM); TRINIDADE, Simla, 12.ii.1966, W. D. Duckworth leg., 1 macho (USNM); VENEZUELA, [Bolivar], Sabana E. B., Akuriman Gran, xi-xii.1940, P. J. Anduze leg., 1 macho (USNM); BRASIL, Roraima, Boa Vista, Tapajós, 30.vi. [sem ano], R. C. Shannon leg., 1 fêmea (USNM); Rio Uraricoera, Ilha de Maracá, 21-30.xi.1987, armadilha de Shannon, J. A. Rafael e equipe leg., 1 fêmea (INPA); Pará, S. J. Pirabas, 25.vii.1978, M. F. Torres leg., 1 macho (MPEG); C. Araguaia, 28.xi.1978, F. F. Ramos leg., 1 macho (MPEG); Seure, 24.ii.1979, P. Eremita leg., 1 macho (MPEG); Belém, Faz. Velha, 18.viii.1970, T. Pimentel leg., 1 macho (MPEG); Bragança, Tracuateua, 31.viii.1988, [coletor anônimo], 1 macho (MPEG); ibidem, 0204.xi.1990, arm. suspensa, 16m, I. S. Gorayeb leg., 2 machos (MPEG); ibidem, F. F. Ramos leg., 1 macho (MPEG); E. F. Bragança, Km 16, 23.vii.[19]56, E. Lobato leg., 1 macho (MPEG); Guamá, 09.v.[19]56, E. Lobato leg., 1 macho (MPEG); Belém, Mocambo, 17.iii.1978, M. F. Torres leg., 1 macho (MPEG); Inhangapi, Castanhal, 27.xi.1971, T. Pimentel leg., 1 fêmea (MPEG); Tucuruí, Puraquequara, 11.viii.1980, [n ${ }^{\circ}$ ] 5630, eq[uipe] Nunes de Mello leg., 1 fêmea (INPA); ibidem, 12.viii.1980, [n ${ }^{\circ}$ ] 5631, 1 fêmea (INPA); ibidem, 14.viii.1980, [n $\left.{ }^{\circ}\right]$ 5633, 1 fêmea (INPA); Unt. Amaz. Taperinha b. [?] Santarém, 11 20.vi.[?]27, Zerny leg., 1 macho (NHMW); Amazonas, Manaus, Colônia Sto. Antônio, 08.vii.1970, T. Pimentel leg., 1 macho (MPEG); 

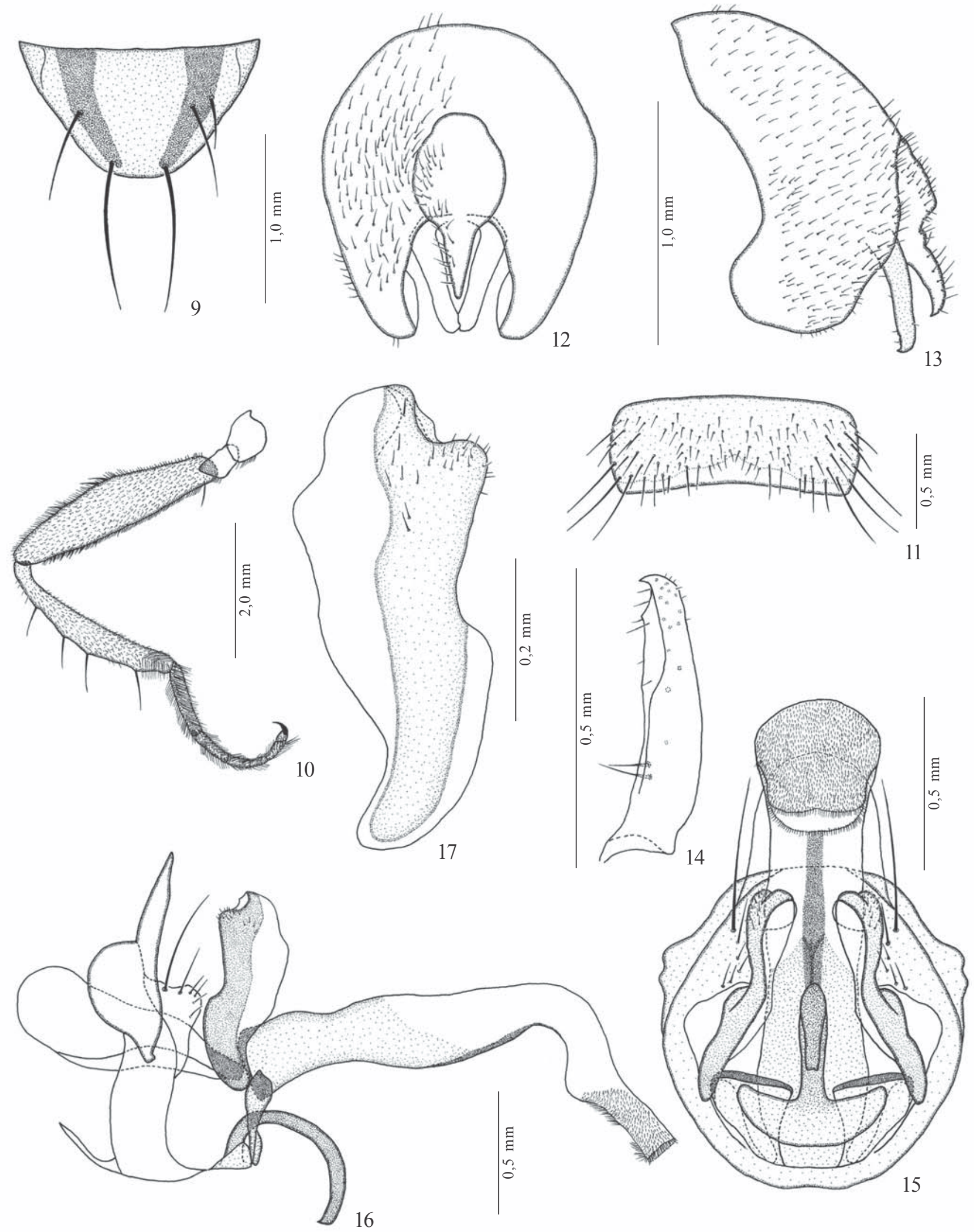

11

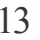

Figs. 9-17. Willistoniella pleuropunctata: 9 (holótipo fêmea), escutelo (vista dorsal); 10-17 (macho): 10, perna posterior esquerda; 11, esternito 5 (vista ventral); 12-13, terminália masculina (vista ventral e lateral, mesma escala); 14, surstilo esquerdo (vista lateral); 15-16, terminália masculina interna (vista ventral e lateral); 17, parâmero esquerdo (vista lateral interna). 
Parque Nacional do Jaú, 16-29.vi.2001, armadilha Shannon, J. F. Vidal leg., 1 fêmea (INPA); Manaus, R[eserva] [Adolpho] Ducke, AM-010, km 26, 253'S 5959'W], 20-27.vii.1988, isca de fruta, Y. Câmara \& F. Xavier leg., 2 fêmeas (INPA); ibidem, 03-10.xi.1988, Y. Camâra \& J. F. Vidal leg., 1 fêmea (INPA); Embrapa, AM-010, Km 31, 25.x.1990, arm[adilha] Shannon, isc[a de] fruta, C[ultura de] guaraná, L. P. Albuquerque \& J. E. Bindá leg., 1 fêmea (INPA); ibidem, 31.x.1990, 1 macho (INPA); ibidem, 28.xii.1990, 1 macho (INPA); ibidem, 17.v.1991, 2 fêmeas (INPA); ibidem, 17.vii.1991, 1 macho (INPA); C[ampus] Univ[ersitário], 24.iii.1979, J. A. Rafael leg., 2 fêmeas (INPA); Conj. Campus Elisios, i-ii.2002, Arm. McPhail, B. Ronchi-Teles leg., 1 macho (INPA); Conj[unto] Jardim Europa, Bairro Ponta Negra, 1523.xi.2002, Arm. de garrafa Pet [Mcphail modificada], em cópula, A. P. C. Marques leg., 1 macho e 1 fêmea (INPA); E[stação] E[xperimental] [de] F[ruticultura] T[ropical] BR-174, km 40, 16.i.1997, McPhail [em] araçá-boi, B. Rochi-Teles leg., 7 machos (INPA); ibidem, Roçadão, [arm. McPhail em] goiaba, 4 fêmeas (INPA); ibidem, 27.ii.1997, araçáboi, 1 macho (INPA); ibidem, 6.iii.1997, araçá-pêra, 1 macho (INPA); ibidem, 24.iv.1997, araçá-pêra, 2 machos (INPA); ibidem, 02.v.1997, araçá-pêra, 1 macho (INPA); ibidem, 08.v.1997, araçá-boi, 1 macho (INPA); ibidem, 22.v.1997, araçá-pêra, 2 machos (INPA); ibidem, araçá-boi, 2 machos (INPA); ibidem, 28.v.1997, goiaba, 5 machos (INPA); ibidem, 05.vi.1997, goiaba, 9 machos (INPA); ibidem, araçápêra, 2 machos (INPA); ibidem, 09.vi.1997, araçá-pêra, 1 macho (INPA); ibidem, 17.vii.1997, sorva, 1 macho (INPA); ibidem, 04.ix.1997, araçá-pêra, 2 machos (INPA); ibidem, 16.x.1997, goiaba, 1 macho (INPA); E[scola] A[grícola] R[ainha dos] A[póstolos], BR174 km 23, 16.i.1997, McPhail [em] bacuri, B. Ronchi-Teles leg., 1 macho (INPA); ibidem, araticum, 2 machos (INPA); ibidem, 30.i.1997, bacuri, 3 machos (INPA); ibidem, 21.iii.1997, abiu, 1 macho (INPA); ibidem, 28.v.1997, araticum, 1 macho (INPA); ibidem, abiu, 1 macho (INPA); ibidem, bacuri, 1 macho (INPA); ibidem, 10.vii.1997, bacuri, 3 machos (INPA); ibidem, 21.viii.1997, bacuri, 1 macho (INPA); ibidem, 23.x.1997, abiu, 1 macho (INPA); ibidem, bacuri, 1 macho (INPA); Presidente Figueiredo, iv.2001, armadilha McPhail, B. RonchiTeles leg., 11 fêmeas (INPA); Com[unidade] S[ão] F[ran]c[isc]o de Assis, AM-240, Km 24, 02 $01^{\prime}$ 'S 5949'W, 01-11.ix.2002, F. Xavier \& U. C. Barbosa leg., 1 fêmea (INPA); Tocantis, Palmas, Chácara São José, $10^{\circ} 17^{\prime} 14^{\prime \prime} \mathrm{S} 48^{\circ} 20^{\prime} 21^{\prime \prime W}$, 20.viii.2002, arm[adilha] McPhail, B. Ronchi-Teles leg., 1 fêmea (INPA); ibidem, Chácara Coquinho, $10^{\circ} 15^{\prime} 63^{\prime \prime} \mathrm{S} 48^{\circ} 18^{\prime} 20^{\prime \prime} \mathrm{W}, 23 . v i i i .2002$, McPhail em acerola, 1 fêmea (INPA); Rondônia, Nova Califórnia, Projeto Reca, 10.v.1997, arm. McPhail, B. Ronchi-Teles leg., 19 fêmeas (INPA); Abunã, Rio Madeira, [sem data], Collection C. W. Johnson, Mann \& Baker leg., 1 macho (MCZ); Sergipe, Estância, xii.1929, R. C. Shannon leg., 1 macho (USNM); Maranhão, Rosário, Igarapé Paraqueú, 20-22.xi.[19]70, Berla leg., 1 fêmea (MZSP); Mato Grosso, Mun[icípio] Três Lagoas, Faz. Floresta, 13-20.ix.1964, Exp. Dpto. Zool., 2 fêmeas e 1 macho (MZSP); Rio Paraqui, xi.[1]935, Worontzou leg., 1 macho (INPA); Distrito Federal, Brasília, ix.[19]69, H. Ebert leg., 1 fêmea (INPA); Goiás, Goianesia, ix.[19]69, H. Ebert leg., 1 macho (INPA); Espírito Santo, iii.1940, R. C. Shannon Collection, 1 macho (USNM); ibidem, iv.1940, Serviço Febre Amarela M. E. S., Bras., [coletor anônimo], 2 machos (USNM); Baixo Guandu, ix.1970, P. C. Elias leg., 1 fêmea e 1 macho (MZSP), 1 fêmea e 1 macho (INPA); Rio de Janeiro, Serviço Febre Amarela, M. E. S., Bras., xii.1937, 1 fêmea (INPA); ibidem, ix.1938, Yel[low] Fev[er] Serv[ice], M. E. S., Brazil, R. C. Shannon leg., 1 macho (INPA); ibidem, Angra, Japuíba, 23.iii.[1]940, Lopes \& Lane leg., 1 macho (USNM); Minas Gerais, Viçosa, xi.[1]958 [coletor anônimo], 1 macho (MZSP), 1 macho (INPA); São Paulo, [sem data], Bruno Pohl leg., 1 macho (MCZ); Araçatuba, Córrego azul, ii.1945, M. P. Barretto leg., 8 fêmeas e 8 machos (MZSP); ibidem, iii.1947, 1 macho (MZSP); ibidem, Rio Jacarecatinga, x.[19]61, Lane \& Rabello leg., 5 machos (MZSP); Santos, [sem data] [coletor anônimo], 2 fêmeas e 1 macho (MZSP); Faz. Itaquerê, Nova Europa, 26.i.1964, K. Lenko leg., 2 fêmeas (INPA), 4 machos (MZSP); ibidem, Boa Esperança do Sul, 18.xii.1964, 1 fêmea e 1 macho (MZSP); Avanhandava, Barra Mansa, ii.[1]946, Barretto leg., 2 fêmeas e 8 machos (MZSP); Ribeirão Preto, Rio Tamanduá, 10.xii.1955, M. P. Barretto leg., 1 macho (MZSP); Porto Cabral, R[io] Paraná, 20-31.iii.1944, Trav. Fo., Carrera
\& E. Dente leg., 3 machos (INPA); ibidem, 01-25.iv.1944, 1 fêmea e 1 macho (MZSP); Peruíbe, xii.1946, M. Carrera leg., 1 fêmea (MZSP); Mun[icípio] Cajuru, Cássia dos Coqueiros, ix.1954, M. P. Barretto leg., 1 fêmea (MZSP); ibidem, xi.1955, 1 fêmea (MZSP); ibidem, ii.1947, 1 fêmea e 2 machos (MZSP); S. Amaro, 08.v.[19]44, Dias-Ramalho leg., 1 macho (MZSP); Barueri, 02.xii.1955, K. Lenko leg., 1 macho (MZSP); Itaporanga, N. B. Antonina, i.[1]946, Barretto leg., 1 fêmea (MZSP); [Santa Catarina], Nova Teutônia, $27^{\circ} 11^{\prime} \mathrm{B}$ [S] 52² $23^{\prime} \mathrm{L}$ [W], ii.1967, Fritz Plaumann leg., 1 fêmea (INPA); ibidem, iii.1967, 1 macho (INPA); ibidem, viii.1967, 1 fêmea e 1 macho (INPA); ibidem, x.1967, 1 macho (MZSP); ibidem, i.1966, 300-500m, 1 fêmea (MZSP); ibidem, xii.1969, 1 macho (MZSP); ibidem, iii.1970, 1 fêmea (MZSP); ibidem, iii.1971, 1 fêmea (MZSP); ibidem, xi.1971, 1 macho (MZSP); ibidem, ii.1972, 1 fêmea (MZSP); ibidem, ii.1973, 1 macho (FMNH); ibidem, iv.1973, 1 fêmea e 1 macho (FMNH); ibidem, ii.1974, 7 fêmeas e 1 macho (FMNH); ibidem, ii.1975, 1 fêmea (FMNH); ibidem, i.1977, 2 fêmeas (FMNH); ibidem, ii.1977, 1 fêmea (FMNH); ibidem, [sem data], 1 fêmea (FMNH); PERU, [Ucayali], Pucallpa, [?].1950, Peter Hocking leg., 1 macho (FMNH); BOLÍVIA, [Santa Cruz], Prov[íncia] Sara, [sem data], Steinbach leg., 1 macho (MCZ); PARAGUAI, [Boqueron], Chaco, [sem data], Fiebrig leg., 1 macho (NHMW); Concepcion, 25.vii.1933, Alb Schulze leg., 1 fêmea (USNM); [Guairã], Villarrica, [?].x.[sem ano], F. Schade leg., 1 macho (MCZ); ibidem, i.1937, 15 machos (USNM); ibidem, vi.1937, 6 fêmeas e 3 machos (USNM); ibidem, vii.1937, 1 fêmea e 4 machos (USNM); ibidem, xi.1937, 2 machos (INPA); ibidem, xii.1937, 1 macho (INPA); ibidem, viii.1938, 1 fêmea e 3 machos (USNM); ibidem, ii.1939, 5 machos (USNM) e 3 fêmeas (INPA); ibidem, 18.iii.1939, [coletor anônimo], 1 macho (USNM); ibidem, 08.iv.[19]39, 1 macho (USNM); ibidem, 10.iv.[19]39, 15 machos (USNM); ibidem, 30.iv.[19]39, 1 macho (USNM).

Variações. Face com coloração uniforme variando do amarelo ao castanho-escuro, na maioria dos exemplares; eventualmente, a carena e as laterais da face apresentam-se avermelhadas; coloração dos artículos antenais variável, com tons alaranjados, ferrugem ou castanhos; flagelo inteiramente castanho, com polinosidade dourada nas faces interna e externa; clípeo, palpo e gena seguindo o padrão de coloração da face; uma cerda extranumerária entre as pós-ocelares eventualmente presente; faixa acrostical de polinosidade prateada ausente; foi observado um exemplar com uma cerda extranumerária entre as cerdas apicais do escutelo. Todos os fêmures inteiramente castanho-escuros, podendo apresentar polinosidade esbranquiçada esparsa nas faces anterior e dorsal, e número de cerdas variável, mas sempre com o mesmo padrão de distribuição. Tíbias inteiramente castanhas.

Comentários. O holótipo fêmea foi examinado e redescrito pela primeira vez. Coletou-se um casal em cópula, o que permitiu a correta associação entre macho e fêmea. No que diz respeito ao padrão de coloração da face, $W$. pleuropunctata pode algumas vezes confundir-se com $W$. ulyssesi sp. nov. e $W$. latiforceps sp. nov., considerando-se que este é um caráter muito variável. Com relação à terminália masculina, $W$. pleuropunctata assemelha-se muito à $W$. ulyssesi sp. nov., entretanto seu surstilo sempre é mais curto (não ultrapassando a margem posterior do epândrio) e mais delgado do que o de $W$. ulyssesi $\mathbf{s p . ~ n o v . , ~ p o d e n d o ~ a s s i m , ~ s e r ~ f a c i l m e n t e ~ s e p a r a d a ~}$ desta espécie. Além disso, o epândrio tem formato mais arredondado, a terminália, como um todo, é menor e a base dos cercos é arredondada, diferindo de todas as outras 

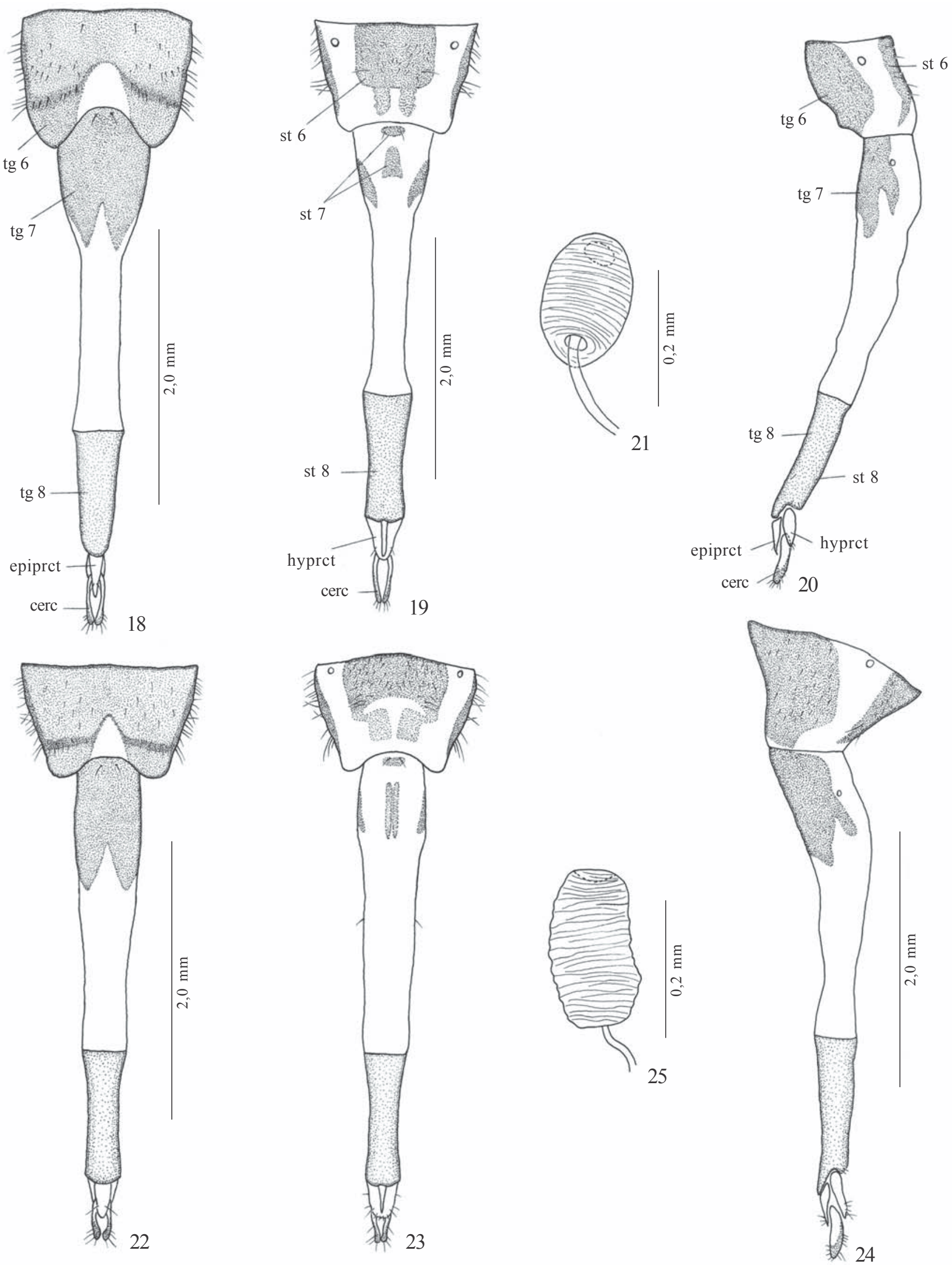

Figs. 18-25. Terminália feminina (vista dorsal, ventral, lateral direita) e espermateca: 18-21, W. latiforceps sp. nov. (parátipo); 22-25, W. pleuropunctata; 19-20 e 22-23 na mesma escala; cerc = cerco; epiprct = epiprocto; hyprct $=$ hipoprocto; $s t=$ esternito; $t \mathrm{~g}=$ tergito. 
espécies do gênero. A separação das fêmeas torna-se difícil sem a dissecção da terminália, que apresenta o segmento 7 bastante membranoso, em vista ventral, com os escleritos do esternito 7 muito pouco esclerotinizados e quase imperceptíveis, o que a distingue das fêmeas das demais espécies.

Observação. Como o gênero era, até então, monotípico, e como a identificação de $W$. pleuropunctata geralmente era feita com base na presença de carena mediana na face (caráter genérico), muitos exemplares deste gênero foram incorretamente identificados. O estudo das terminálias feminina e, principalmente, masculina irá provavelmente acarretar mudanças na ampla distribuição de $W$. pleuropunctata.

\section{Willistoniella spatulata sp. nov. (Figs. 26-32, 40-43, 50)}

Diagnose. Face amarelada ou castanha com mancha castanho-escura e larga cobrindo toda a carena ou ainda face inteiramente castanha a negra; terminália feminina: tergito 7 com reentrância em forma de V na extremidade posterior; esternito 7 composto apenas por uma pequena placa basal transversal com um par de cerdas. Esternito 5 do macho com 2 cerdas mais longas nos ângulos póstero-laterais; terminália masculina: surstilo delgado com a porção apical alargada e cerdosa, lembrando a forma de uma espátula.

Holótipo macho. Comprimento do corpo: 10,3 mm. Comprimento e largura da asa: 7,6 $\mathrm{mm}$ x 2,3 mm.

Cabeça: fronte castanho-escura; cerca de 9 cerdas pósoculares; face amarelada com uma mancha castanha larga cobrindo toda a carena; artículos antenais castanho-escuros; flagelo com polinosidade dourada esparsa na face interna; clípeo, palpo, gena e pós-gena também castanho-escuros; gena e pós-gena com cerdas ruivas; 7 cerdas no esclerito parafacial.

Tórax: escuto castanho-escuro, com as seguintes faixas de polinosidade: 1 acrostical prateada esparsa, estreita e incompleta, limitando-se à região pré-sutural; 1 dorsocentral dourada que se estende até o ápice do escutelo e 1 lateral dourada estendendo-se do lóbulo pós-pronotal até o calo pósalar; cerdas destacadas: 2 pós-pronotais (a mais interna reduzida), 2 notopleurais (1 extranumerária reduzida no lado direito, ao lado da notopleural mais anterior), 1 supra-alar présutural reduzida, 1 supra-alar pós-sutural, 1 pós-alar, 2 intraalares (a anterior reduzida), 1 intra-pós-alar, 1 dorsocentral préescutelar pós-sutural reduzida e 1 acrostical pós-sutural préescutelar. Escutelo castanho-escuro com 1 cerda apical e 1 marginal. Subescutelo castanho com faixa de polinosidade dourada. Pleura castanho-escura; cerca de 6-8 cerdas na borda superior do espiráculo metatorácico.

Asa (Fig. 50): tégula com 4 cerdas destacadas; medidas das seções da veia Costa: I $1.2 \mathrm{~mm}$, II $1.7 \mathrm{~mm}$, III 2 mm, IV 1.3 $\mathrm{mm}, \mathrm{V} 0.5 \mathrm{mme}$ VI $0.3 \mathrm{~mm}$.

Pernas: coxas com polinosidade prateada esparsa, com cerdas negras. Trocânteres castanhos. Fêmures castanhoescuros, sem polinosidade. Fêmur anterior com várias cerdas dorsais desalinhadas, margem anterior da face ventral com uma fileira de $8-9$ cerdas, as 2 basais menores, margem posterior ventral com uma fileira de 10 cerdas. Fêmur médio com uma fileira de 16-17 cerdas curtas na margem anterior da face ventral, a cerda basal mais fraca e uma fileira de 14 cerdas na margem póstero-ventral. Fêmur posterior com várias cerdas dorsais desalinhadas, uma fileira de 11-12 cerdas curtas na margem anterior da face ventral e 10 cerdas na margem posterior. Tíbias castanho-escuras; tíbia posterior com 4 cerdas na margem póstero-dorsal; base das tíbias média e posterior com pequena mancha de polinosidade prateada nas faces anterior e posterior. Tarsômero 1 coberto por polinosidade esbranquiçada dorsal e intensa pilosidade dourada ventral; demais tarsômeros castanho-escuros.

Abdome: castanho-escuro; esternito 5 com 2 cerdas mais longas nos ângulos póstero-laterais; várias cerdas de tamanhos variáveis uniformemente distribuídas na porção posterior, próximo à região membranosa, 2 cerdas maiores na parte central (Fig. 26); terminália: cerco moderadamente cerdoso, com cerdas uniformemente distribuídas nas laterais e no ápice, as do ápice mais longas (Figs. 27-28); surstilo delgado com a porção apical mais alargada e cerdosa, lembrando a forma de uma espátula, pouco mais longo que o cerco, não ultrapassando a margem posterior do epândrio (Figs. 27-29); parâmero estreitado (Figs. 30-32); epifalo moderadamente engrossado (Fig. 30-31); edeago dobrado para baixo no $1 / 3$ distal, cerca de 2 vezes o comprimento do parâmero (Figs. 30-31).

Fêmea. Comprimento do corpo: $11 \mathrm{~mm}$. Comprimento e largura da asa: 7,0 $\mathrm{mm} \times 2,3 \mathrm{~mm}$.

Como no macho, exceto pelo que segue: medidas das seções da veia Costa: I $1.3 \mathrm{~mm}$, II $1.7 \mathrm{~mm}$, III $2 \mathrm{~mm}$, IV $1.2 \mathrm{~mm}$, V $0.6 \mathrm{~mm}$ e VI $0.3 \mathrm{~mm}$. Terminália: tergito 7 com reentrância em forma de $\mathrm{V}$ na extremidade posterior, com projeção que se estende látero-ventralmente, vísivel na face ventral (Figs. 4042 ); esternito 7 composto apenas por uma placa basal transversal com um par de cerdas (Fig. 41); espermateca arredondada com numerosas estrias transversais (Fig. 43).

Distribuição geográfica. Honduras, Panamá, Venezuela, Colômbia, Equador e Brasil (Pará e Amazonas).

Material-tipo examinado. Holótipo macho (INPA), etiquetado: BRASIL, Amazonas, Beruri, Est[rada] do INCRA, km 3, 03056'62"S $61^{\circ} 21^{\prime} 02^{\prime \prime} \mathrm{W}, 28 . i x-09 . x .2002$ (etiqueta impressa branca)/ F. X. Filho \& U. Barbosa leg. (etiqueta impressa branca)/ Holótipo, Willistoniella spatulata, Marques \& Ale-Rocha (etiqueta impressa vermelha). Condição do holótipo: em perfeito estado de conservação, não dissecado. Parátipos. HONDURAS, Manatee, in 4.jan.1902, in coroa palm, 1 fêmea (NHMW); [Cortés], Tela, Lancetilla creek, 16.iii.1923, T. H. Hunbbell leg., 1 fêmea (INPA); [PANAMÁ], [Panamá], [Parque Nacional] Campana, ix.1937, "fruit fly trap", nº 3964, J. Zetek leg., 1 fêmea (USNM); C[anal] Z[one], New Gatun, 08.x.1917, Harold Morrison leg., 1 fêmea (INPA); VENEZUELA, T[erritorio] $F[$ ederal] $A$ [mazonas], $7 \mathrm{Km}$ E. San Carlos de Rio Negro, 10-12.iii.1984, O. Flint \& J. Lounton leg., 1 macho (USNM); COLÔMBIA, Boyaca, 

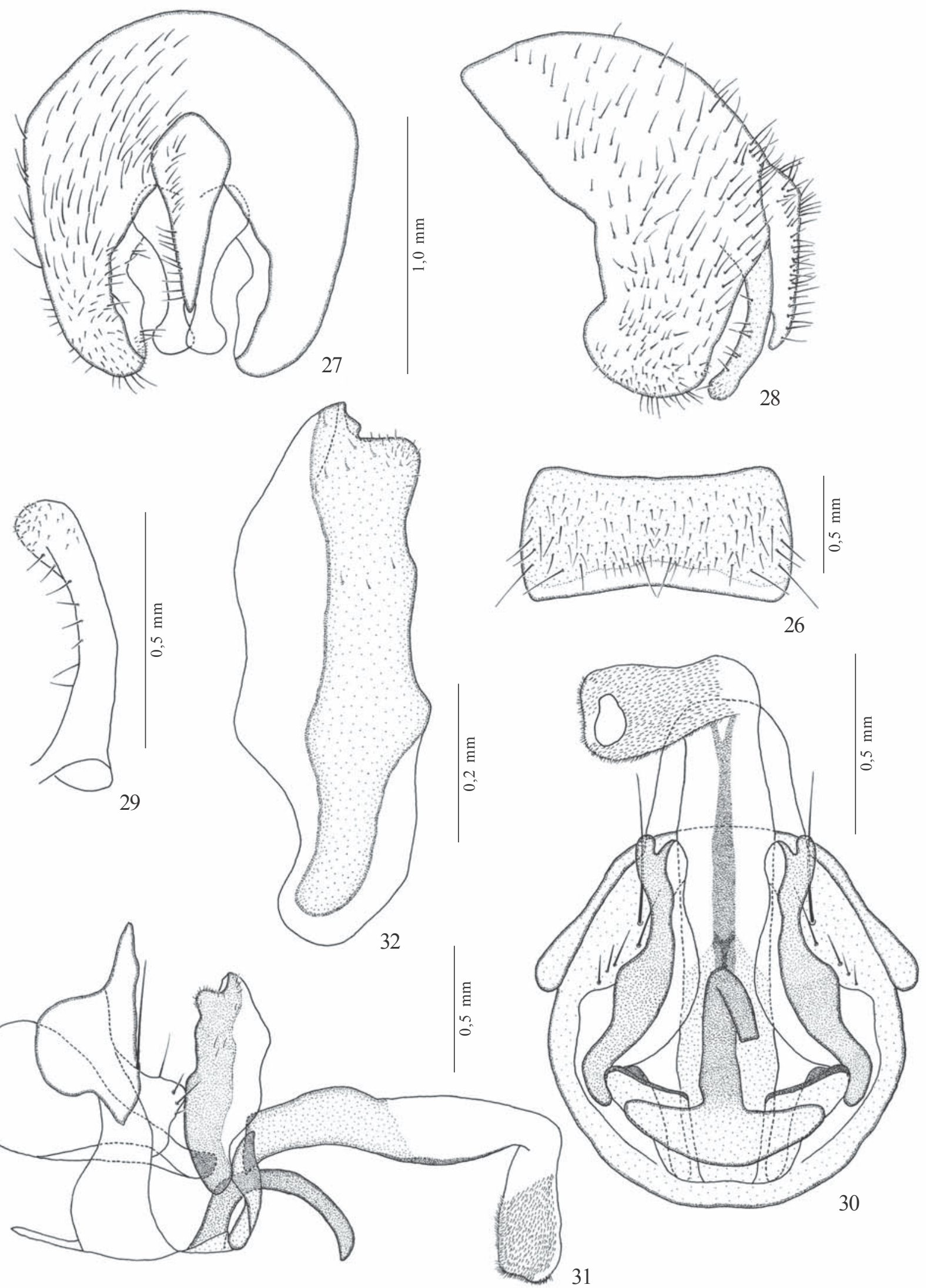

Figs. 26-32. Willistoniella spatulata sp nov. (parátipo macho): 26, esternito 5 (vista ventral); 27-28, terminália masculina (vista ventral e lateral, mesma escala); 29, surstilo esquerdo (vista lateral); 30-31, terminália masculina interna (vista ventral e lateral); 32, parâmero esquerdo (vista lateral interna). 
Muzo, alt. 900 m, vii.1936, A. H. Sturtevant Collection 1970, J. Bequaert leg., 1 fêmea (USNM); EQUADOR, [Bolivar], Balzapamba, [sem data], R. Haensch S. leg., 1 fêmea (NHMW); BRASIL, Pará, Tucuruí, Vila Brava, 22.vi.1980, [n ${ }^{\circ}$ 5558, eq[uipe] Nunes de Mello leg., 2 machos (INPA); Marajó, Breves, Rio Caruacá, 05.viii.1988, J. Dias leg., 2 machos (MPEG); ibidem, isca [de] abacaxi, 1 macho (MPEG); ibidem, 06.viii.1988, 1 macho (MPEG); ibidem, 08.viii.1988, 1 macho (MPEG); ibidem, 09.viii.1988, 1 macho (MPEG); ibidem, isca [de] melão, 1 macho (MPEG); ibidem, 5.viii.1988, R. Santos leg, 1 macho (MPEG); Benevides, Est. Neópolis, Sítio D. Doca, [?].vii.1991, W. Overal leg., 1 macho (MPEG); Serra Norte, N1, 29.vi.1984, c[oleta] noturna, [coletor anônimo], 1 macho (MPEG); Marudá, 20.xi.1971, T. Pimentel leg., 1 macho (MPEG); Amazonas, Rio Unini, Comunidade Democracia, 14.vi.1996, R. Ferreira leg., 2 fêmeas (INPA); ibidem, Paraná do Bacaba, 13-19.vi.1996, 1 fêmea (INPA); Presidente Figueiredo, iv.2001, arm[adilha] McPhail, B. Ronchi-Teles leg., 11 fêmeas (INPA); ibidem, 1 macho (MCZ); Com[unidade] S[ão] F[rancis]co de Assis, AM-240, Km 24, 02 $01^{\prime}$ 'S 59 49' W, 01-11.ix.2002, isca de banana fermentada, F. Xavier \& U. Barbosa leg., 2 fêmeas (INPA); Beruri, Est[rada] do INCRA, Km 3, 0356'62"S 61 $21^{\circ}$ '02"W, 28.ix-09.x.2002, U. Barbosa \& X. Filho leg., 8 fêmeas (INPA); Manaus, Colônia Sto. Antônio, 08.vii.1970, T. Pimentel leg., 1 macho (MPEG); ibidem, 10.vii.1970, 1 macho (MPEG); ibidem, 11.vii.1970, 1 macho (MPEG); ibidem, Conj[unto] Jardim Europa, Bairro Ponta Negra, 1523.xi.2002, arm[adilha] de garrafa Pet, em cópula, A. P. C. Marques leg., 1 macho e 1 fêmea (INPA); ibidem, Conj[unto] Campus Elisios, iii.2002, arm[adilha] McPhail, B. Ronchi-Teles leg., 1 fêmea (INPA); ibidem, Campus Univ[ersitário], 20.viii.1978, arm[adilha] Malaise, J. A. Rafael leg., 1 macho (INPA); ibidem, 09.ix.1978, 1 fêmea e 1 macho (INPA); ibidem, 07.x.1978, 2 fêmeas (INPA); ibidem, 04.xi.1978, 1 macho (INPA); ibidem, 25.xi.1978, 2 fêmeas e 2 machos (INPA); ibidem, 2.xii.1978, 1 fêmea e 1 macho (INPA); ibidem, 9.xii.1978, 1 fêmea (INPA); ibidem, 13.i.1979, 1 fêmea (INPA); ibidem, 21.iv.1979, 1 macho (INPA); ibidem, 9.xii.1979, 1 macho (INPA); ibidem, 23.xii.1979, 1 macho (INPA); ibidem, 29.vi.1982, 1 fêmea (INPA); ibidem, 17-19.v.1988, arm[adilha] Shannon, isca [de] fezes, Márcia Castilho \& J. Elias Bindá leg., 1 macho (INPA); ibidem, 19-21.v.1988, arm[adilha] p[ara] Diptera, isca [de] fruta, 3 machos (INPA); R[eserva] [Adolpho] Ducke, [AM-010, km 26, $2^{\circ} 53^{\prime} \mathrm{S}$ 5959'W], 8.xi.1977, L. P. Albuquerque leg., 1 macho (INPA); ibidem, 21.xi.2001, armadilha Shannon, palmeiras de buriti, J. F. Vidal leg., 4 fêmeas (INPA); ibidem, 2 fêmeas e 1 macho (FMNH); ibidem, 6.viii.2002, arm. McPhail, área aberta, baixio, E. F. Soares \& A. L. Pinheiro leg., 1 fêmea (INPA); ibidem, platô, 5 fêmeas (INPA); ibidem, 6-16.ix.2002, baixio, 3 fêmeas (INPA); ibidem, 10.ix.2002, platô, 2 fêmeas (INPA); ibidem, 6-13.ix.2002, platô, 1 fêmea (INPA); ibidem, 10.ix.2002, mata, platô, 4 fêmeas (INPA); ibidem, baixio, Ig[arapé] Barro Branco, 1 fêmea (INPA); ibidem, 6-16.ix.2002, 1 fêmea (INPA); ibidem, 24-28.vii.2000, clareira, [armadilha Shannon], isca de fruta, R. Ale-Rocha, J. F. Vidal \& A. P. Marques leg., 1 macho (INPA); ibidem, 21-25.viii.2000, 1 macho (INPA); ibidem, 25-29.ix.2000, 1 macho (INPA); ibidem, 21-25.v.2001, 1 fêmea e 2 machos (INPA); ibidem, 2 fêmeas (MZSP); ibidem, 23-27.vii.2001, 4 fêmeas (INPA); ibidem, 21-25.v.2001, mata, 1 fêmea (INPA); ibidem, 16-19.v.1988, isca de fruta, Y. Câmara \& F. Xavier leg., 1 macho (INPA); ibidem, 2428.vi.1988, 1 macho (INPA); ibidem, 03.xi.1988, arm[adilha isca] de fezes, 24 m, Y. Câmara \& J. E. Bindá leg., 2 machos (INPA); ibidem, 10.xi.1988, $8 \mathrm{~m}, 1$ macho (INPA); ibidem, 03-10.xi.1988, isca de fruta, Y. Câmara \& J. F. Vidal leg., 1 macho (INPA); ibidem, 16.iii06.iv.1989, 1 macho (INPA); Embrapa, AM- 010, Km 31, 10.ix.1990, arm[adilha] Shannon, Isc[a] [de] Fruta, C[ultura] [de] Andiroba, L. P. Albuquerque \& J. Bindá leg., 1 macho (INPA); ibidem, 28.viii.1991, 1 fêmea (INPA); ibidem, 3.ix.1991, 1 fêmea (INPA); ibidem, 11.ix.1991, 2 fêmeas (MPEG); ibidem, 17.ix.1991, 1 macho (INPA); ibidem, 3.ix.1990, C[ultura de] Cacau, 1 macho (USNM); ibidem, 31.x.1990, 1 macho (INPA); ibidem, 1 macho (MZSP); ibidem, 28.xi.1990, 1 macho (INPA); ibidem, 22.ix.1991, 1 fêmea (INPA); ibidem, 2.x.1991, 2 fêmeas (INPA); ibidem, 1 fêmea (MCZ); ibidem, 6.xi.1991, 1 fêmea e 1 macho (INPA); ibidem, 12.xii.1991, 2 fêmeas (INPA); ibidem, 26.xii.1991, 1 fêmea (INPA); ibidem, 31.x.1990, [em] C[ultura de]
Guaraná, 1 macho (INPA); ibidem, 30.i.1991, 1 macho (INPA); ibidem, 14.viii.1991, 1 fêmea (INPA); ibidem, 25.ix.1991, 1 fêmea (INPA); ibidem, 28.viii.1991, Capoeira, 1 fêmea (INPA).

Variações: fronte homogeneamente castanho-clara ou com a margem anterior alaranjada; 8-10 cerdas pós-oculares presentes; face inteiramente escura, castanha a negra, ou castanha com mancha escura e larga cobrindo toda a carena; artículos antenais amarelados, alaranjados ou castanhos; flagelo unicolorido ou mais escuro na margem dorsal; gena castanho-clara; 6-9 cerdas no esclerito parafacial; faixa acrostical de polinosidade prateada ausente; a maioria dos exemplares com apenas 2 notopleurais; 1-2 pós-pronotais; pernas castanho-claras; número de cerdas das pernas variável, mas sempre com o mesmo padrão de distribuição; tíbia posterior com 5 cerdas póstero-dorsais em alguns exemplares.

Comentários. Com relação à coloração da face, assemelhase à $W$. ulyssesi sp. nov., mas geralmente a mancha castanha que cobre a carena é mais larga e na maioria das vezes a face toda é mais escura, com tons castanhos, e não amarelada como naquela espécie. A terminália masculina assemelha-se a de $W$. ulyssesi sp. nov., no aspecto geral, entretanto, o macho possui surstilo em forma de espátula, delgado com o ápice arredondado e um pouco mais alargado, o que o torna inconfundível; a terminália feminina é parecida com a de $W$. latiforceps sp. nov., porém em $W$. spatulata $\mathbf{s p . ~ n o v . ~ o ~ e s t e r n i t o ~} 7$ não possui uma placa sub-basal longitudinal, sendo formado apenas por uma placa basal transversal com um par de cerdas. Além disso a espermateca é um pouco menor, aproximadamente arredondada, com estriações.

Etimologia. Do Latim, spatula = espátula, daí o epíteto específico 'spatulata' referindo-se ao formato do surstilo.

\section{Willistoniella ulyssesi sp. nov.} (Figs. 33-39, 44-47, 51)

Willistoniella pleuropunctata; Prado, 1963: 468 (cabeça do macho, identificação errônea); Steyskal, 1987: 943 (terminália feminina, identificação errônea); Ramírez-García \& Hernández-Ortiz, 1994: 72-75 (terminália masculina, identificação errônea).

Holótipo macho. Comprimento do corpo: $11 \mathrm{~mm}$. Comprimento e largura da asa: 7,5 mm x 2,5 mm.

Cabeça: fronte castanha, a margem anterior alaranjada; cerca de 9 cerdas pós-oculares; face amarelada com uma faixa estreita e contínua na carena e margens laterais castanhas; artículos antenais alaranjados; clípeo castanho; palpo castanho-escuro; gena e pós-gena castanhas com cerdas ruivas; 9 cerdas no esclerito parafacial.

Tórax: escuto castanho-escuro, com as seguintes faixas de polinosidade: 1 acrostical prateada esparsa, estreita e incompleta, limitando-se à região pré-sutural do escuto; 1 dorsocentral dourada que se estende até o ápice do escutelo e 1 lateral dourada estendendo-se do lóbulo pós-pronotal até o calo pós-alar; cerdas destacadas: 2 pós-pronotais (a mais 

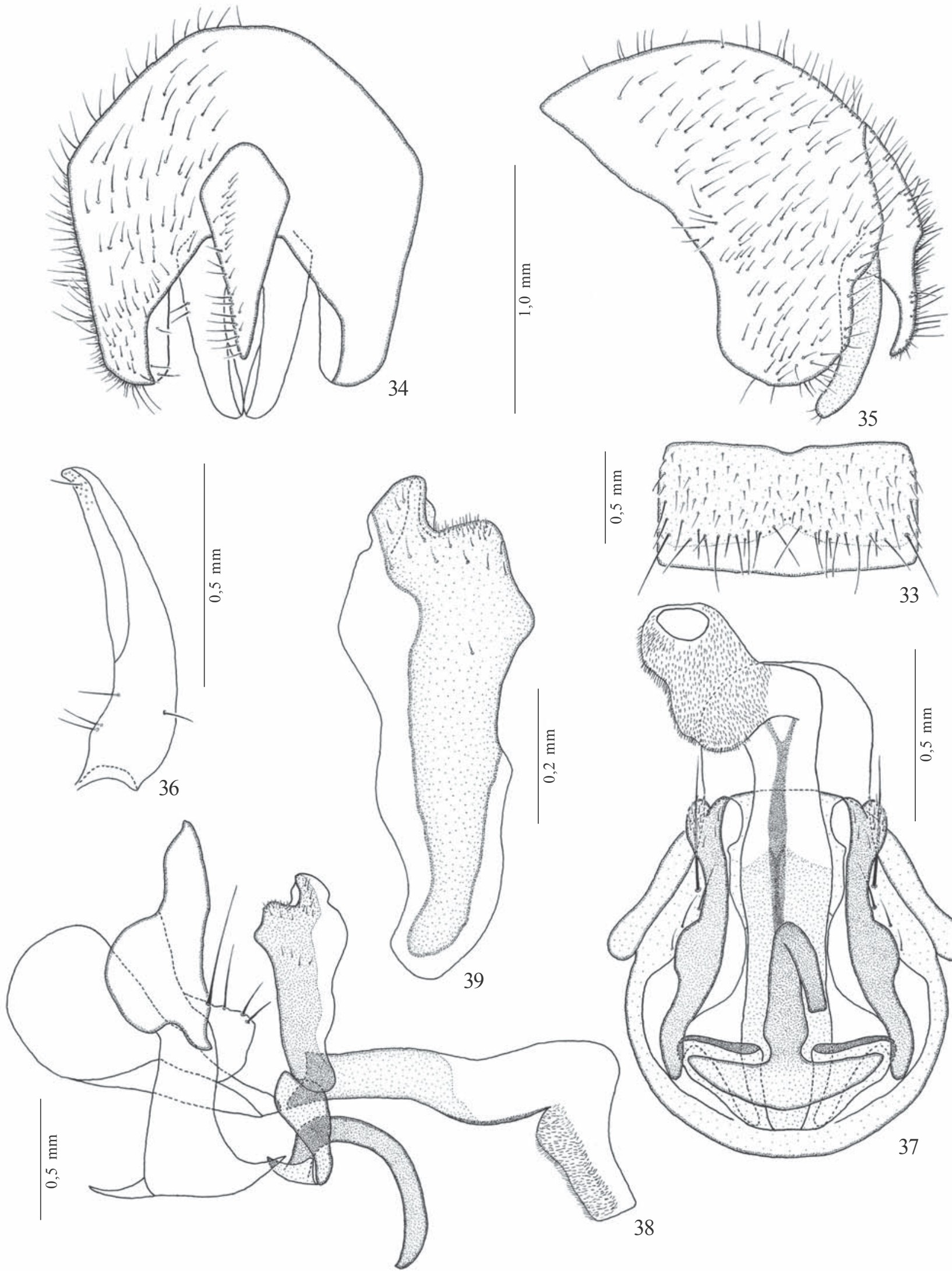

Figs. 33-39. Willistoniella ulyssesi sp. nov. (parátipo macho): 33, esternito 5 (vista ventral); 34-35, terminália masculina (vista ventral e lateral, mesma escala); 36, surstilo esquerdo (vista lateral); 37-38, terminália masculina interna (vista ventral e lateral); 39, parâmero esquerdo (face lateral interna). 
interna reduzida), 2 notopleurais, 1 supra-alar pré-sutural reduzida, 1 supra-alar pós-sutural, 1 pós-alar, 2 intra-alares (a anterior reduzida); 1 intra-pós-alar (1 extranumerária no lado esquerdo), 1 dorsocentral pré-escutelar pós-sutural reduzida e 1 acrostical pós-sutural adiante do escutelo. Escutelo castanho-escuro com 1 cerda apical e 1 marginal. Subescutelo castanho com faixa de polinosidade dourada. Pleura castanhoescura; cerca de 8 cerdas na borda superior do espiráculo metatorácico.

Asa (Fig. 51): tégula com 4 cerdas destacadas; medidas das seções da veia Costa: I $1.8 \mathrm{~mm}$, II $2 \mathrm{~mm}$, III $1.8 \mathrm{~mm}$, IV 1.5 $\mathrm{mm}, \mathrm{V} 0.7 \mathrm{mme}$ VI $0.3 \mathrm{~mm}$.

Pernas: coxas cobertas por polinosidade prateada esparsa, com cerdas negras. Trocânteres castanhos. Fêmures inteiramente castanhos, sem polinosidade. Fêmur anterior com várias cerdas dorsais desalinhadas; margem anterior da face ventral com uma fileira de 10 cerdas, sendo a mais basal menor e mais fraca, margem posterior com uma fileira de 9 cerdas curtas. Fêmur médio com uma fileira de 13 cerdas curtas na margem anterior da face ventral e outra de 15 cerdas na margem posterior. Fêmur posterior com várias cerdas dorsais desalinhadas; uma fileira de 10 cerdas curtas na margem anterior da face ventral e 10 cerdas na margem posterior. Tíbias castanhas; tíbia posterior com 4 cerdas destacadas na margem póstero-dorsal; base das tíbias média e posterior com pequena mancha de polinosidade prateada nas faces anterior e posterior. Tarsômero 1 coberto por polinosidade dorsal esbranquiçada e intensa pilosidade ventral dourada; demais tarsômeros castanho-escuros.

Abdome: castanho-escuro; esternito 5 largo, com 1 cerda mais longa no ângulo póstero-lateral, e cerdas pouco menores ao redor desta; várias cerdas de tamanhos variáveis (mais longas que em $W$. pleuropunctata) uniformemente distribuídas na porção posterior, próximo à região membranosa (Fig. 33). Terminália: cerco moderadamente cerdoso e longo, com cerdas uniformemente distribuídas nas laterais e no ápice, estas últimas mais longas (Figs. 34-35); surstilo delgado, com ápice afilado, mais longo que o cerco, ultrapassando a margem posterior do epândrio (Figs. 34-36); epifalo e parâmero engrossados (Figs. 37-39); edeago dobrado para baixo no $1 / 3$ distal, cerca de 2 vezes o comprimento do parâmero (Figs. 37-38).

Fêmea. Comprimento do corpo: 10,2 mm. Comprimento e largura da asa: $7,8 \mathrm{~mm} \times 2,5 \mathrm{~mm}$.

Como no macho, exceto pelo que segue: medidas das seções da veia Costa: I $1.3 \mathrm{~mm}$, II $2 \mathrm{~mm}$, III $2 \mathrm{~mm}$, IV $1.6 \mathrm{~mm}, \mathrm{~V}$ $0.6 \mathrm{~mm}$ e VI $0.3 \mathrm{~mm}$. Coloração da face como no macho ou, como o observado na maioria, a face inteiramente amarela, castanha ou avermelhada, sem manchas bem definidas. Terminália: tergito 7 com reentrância em forma de U invertido na extremidade posterior (Fig. 44); esternito 7 composto por uma pequena placa basal com um par de cerdas e uma placa sub-basal maior com cerca de 4 saliências consecutivas, formando pequenas ondulações, bem visíveis em vista lateral (Figs. 45-46); espermateca alongada com numerosas estrias transversais (Fig. 47).
Distribuição geográfica. México, Guatemala, Belize, Honduras, Costa Rica, Panamá, Trinidade, Venezuela, Equador, Peru, Bolívia, Paraguai, Brasil (Acre, Roraima, Amapá, Pará, Amazonas, Rondônia, Goiás, Espírito Santo, Rio de Janeiro e Paraná).

Material-tipo examinado. Holótipo macho (INPA), etiquetado: BRASIL, Amazonas, Manaus, R[eserva Adolpho] Ducke, [AM-010,

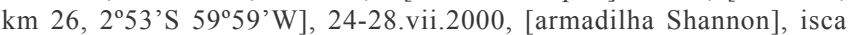
de fruta, mata (etiqueta impressa branca)/ R. Ale-Rocha, J. F. Vidal \& A. P. Marques leg. (etiqueta impressa branca)/ Holótipo, Willistoniella ulyssesi, Marques \& Ale-Rocha (etiqueta impressa vermelha).

Condição do holótipo. Tíbia e tarso da perna anterior esquerda quebrados; as demais pernas e o restante do espécime em perfeito estado de conservação; terminália não dissecada.

Parátipos. MÉXICO, Vera Cruz, Tejeria, 04.vii.[19]41, 1 macho (INPA); GUATEMALA, [Izabal], Pto. Barrios, 20.iv.1924, 1 macho e 1 fêmea (MCZ); HON[DURAS], [Cortés], Tela, Lacentilla, 13.viii.[19]31, D. M. Bates leg., 1 macho (INPA); PANAMÁ, C[anal] Z[one], [Parque Nacional] Barro Colorado, 01.viii.1924, N. Banks leg., 1 macho (MCZ); ibidem, 24.vii.1924, 1 macho (MCZ); ibidem, Corozal, [sem data], J. Zetek leg., 1 macho (FMNH); ibidem, Tabernilla, [?].vi.[sem ano], August Busck leg., 2 machos (USNM); ibidem, Ancon, Emg., 05.v.[19]26, J. Zetek leg., 6 machos (USNM); ibidem, 07.v.[19]26, 1 macho (USNM); BRASIL, Roraima, Rio Uraricoera, Ilha de Maracá, 21-30.xi.1987, inseticida (fogging), J. A. Rafael e equipe leg., 1 fêmea (INPA); ibidem, armadilha Shannon, 2 machos (INPA); ibidem, 1-4.iii.1988, arm. de Shannon, eq[uipe] J. A. Rafael leg., 1 fêmea e 3 machos (INPA); Acre, Rio Branco, P[ar]q[ue] Zoobotânico, UFAC, 13.v.1997, McPhail, B. Ronchi-Teles leg., 1 fêmea (INPA); Pará, Oriximiná, Bôca do Cuminá-Miri, 19-26.i.1968, Exp. Perm. Amaz., 1 fêmea e 1 macho (MZSP); Faz. Taperinha próx[imo a] Santarém, 01-11.ii.1968, Exp. Perm. Amaz., 1 macho (MZSP); ibidem, xi.1969, 1 fêmea (MZSP); Tucuruí, Vila Brava, 22.vi.1980, [nº] 5558, eq[uipe] Nunes de Mello leg., 1 fêmea e 5 machos (INPA); ibidem, 2 machos (INPA); ibidem, 27.vi.1980, [n ${ }^{\circ}$ ] 5577, 1 macho (INPA); ibidem, Jatobal, 4.viii.1980, [ $\left.\mathrm{n}^{\circ}\right]$ 5559, 2 fêmeas e 2 machos (INPA); Tucuruí, viii.1980, $\left[^{\circ}\right]$ 5639, 2 fêmeas (INPA); Tucuruí, Ig. do Pitinga, 10.iv.[19]81, [ ${ }^{\circ}$ ] 5749, 1 fêmea (INPA); Tucuruí, R[io] Tocantins, próx[imo] [a] cid[ade] N. dos Patos, 11.iv.[19]81, [n ${ }^{\circ}$ ] 5765, 1 fêmea (INPA); ibidem, [nº 5766, 1 fêmea (INPA); Tucuruí, Bagagem, 4.viii.1980, [n ${ }^{\circ}$ ] 5611, 1 fêmea (INPA); ibidem, 6.viii.1980, [nº 5614, 1 fêmea (INPA); ibidem, Puraquequara, 11.viii.1980, [nº 5630, 5 fêmeas (INPA); ibidem, 12.viii.1980, [n ${ }^{\circ}$ ] 5631, 19 fêmeas (INPA); ibidem, 13.viii.1980, $\left[\mathrm{n}^{\circ}\right] 5632,1$ fêmea (INPA); ibidem, 14.viii.1980, $\left[\mathrm{n}^{\circ}\right]$ 5633, 4 fêmeas (INPA); Serra Norte, Est. Serraria, 07.viii.1984, M. Zanuto leg., 1 macho (MPEG); ibidem, 07.vi.1983, isca de carne, W. França leg., 1 fêmea (MPEG); ibidem, Caldeirão, 03-05.vii.1986, armadilha Shannon, 1 fêmea e 1 macho (MPEG); ibidem, Salobo, 2123.x.1984, armadilha suspensa, 20m, 1 fêmea (MPEG); ibidem, Manganes, 11-13.x.1986, armadilha Shannon, M. Martins leg., 2 machos (MPEG); ibidem, 13.x.1986, 1 macho (MPEG); ibidem, N2, 08.x.1986, armadilha Shannon, J. Dias leg., 1 macho (MPEG); ibidem, Fofoca, 07-10.ix.1985, armadilha suspensa, 1,5m, W. França leg., 1 macho (MPEG); Amazonas, P[arque] N[acional] [do] Jaú, 1629.vi.2001, armadilha Shannon, J. F. Vidal leg., 1 fêmea (INPA); ibidem, Rio Unini, Sítio Nunes, 0140’31"S 614’34"W, 20-23.xi.1995, Terra Firme, armadilha Malaise, A. L. Henriques \& J. F. Vidal leg., 1 fêmea (INPA); ibidem, armadilha Suspensa, $15 \mathrm{~m}, 1$ macho (INPA); [Parque Nacional do Jaú], Rio Unini, Paraná do Bacaba, 12-17.vi.1996, R. Ferreira leg., 1 macho (INPA); Beruri, Est[rada] do INCRA, Km 3,

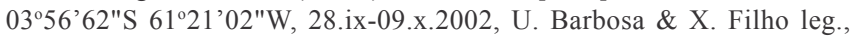
2 fêmeas (INPA); ibidem, 4 fêmeas (INPA); ibidem, 4 fêmeas (INPA); ibidem, em cópula, 1 fêmea e 1 macho (INPA); Embrapa, AM- 010, 

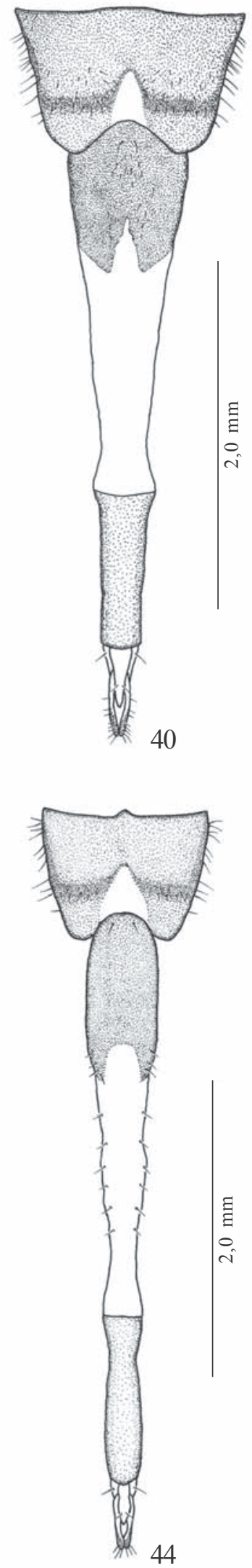

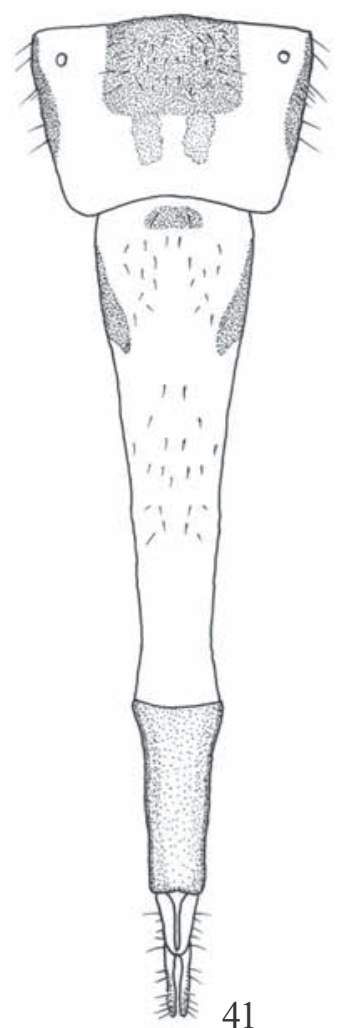

41

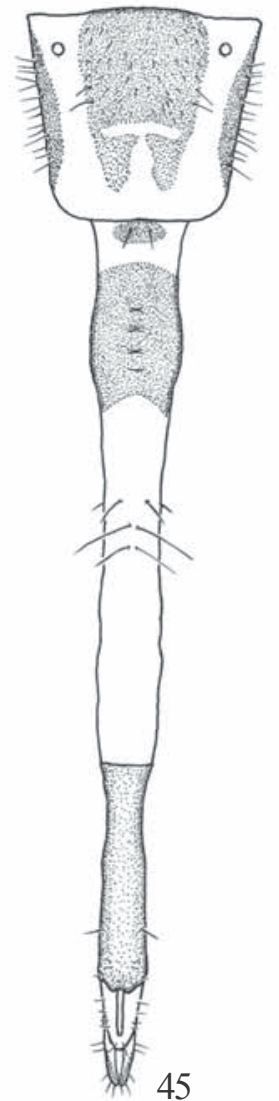

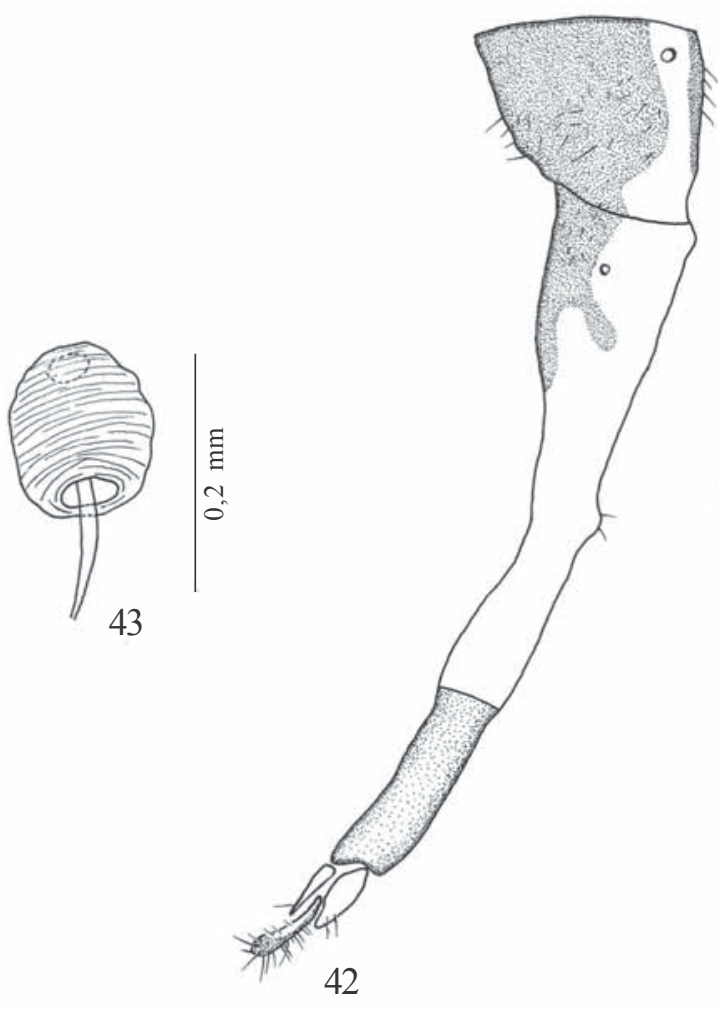

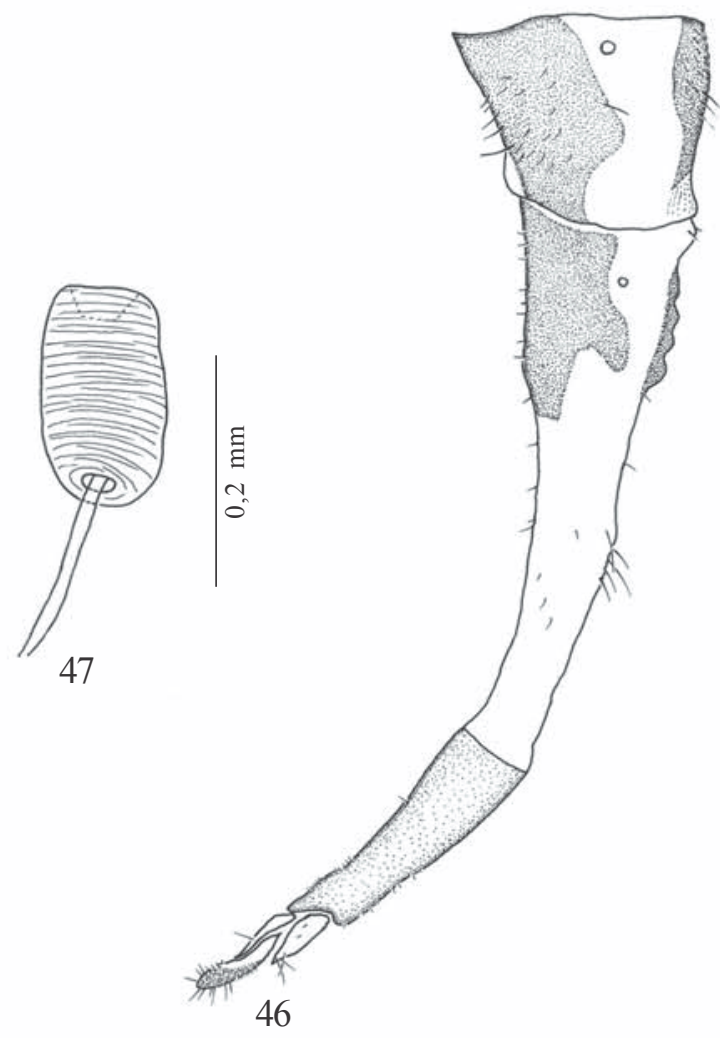

Figs. 40-47. Terminália feminina (vista dorsal, ventral, lateral direita) e espermateca: 40-43, W. spatulata sp. nov. (parátipo); 44-47, W. ulyssesi sp. nov. (parátipo); 40-42 e 44-46 na mesma escala. 
Km 31, 10.ix.1990, arm[adilha] Shannon, Isc[a] [de] Fruta, C[ultura] [de] Andiroba, L. P. Albuquerque \& J. E. Bindá leg., 1 macho (INPA); ibidem, 16.x.1990, 1 fêmea (INPA); ibidem, 10.ix.1990, 2 machos (INPA); ibidem, 20.ii.1991, 1 fêmea (INPA); ibidem, 15.iii.1991, 1 fêmea (INPA); ibidem, 11.ix.1991, 1 fêmea e 1 macho (INPA); ibidem, 17.ix.1991, 1 fêmea (FMNH); ibidem, 26.iii.1992, 1 fêmea (INPA); ibidem, 3.ix.1990, C[ultura] [de] Cacau, 1 fêmea (INPA); ibidem, 1 macho (FMNH); ibidem, 26.ix.1990, 2 fêmeas (INPA); ibidem, 21.xi.1990, 1 macho (INPA); ibidem, 5. xii.1990, 1 macho (INPA); ibidem, 12.xii.1990, 1 fêmea (INPA); ibidem, 16.i.1991, 1 macho (INPA); ibidem, 2.iv.1991, 1 fêmea (INPA); ibidem, 24.v.1991, 1 fêmea (INPA); ibidem, 17.vii.1991, 1 fêmea (FMNH); ibidem, 14.viii.1991, 2 machos (INPA); ibidem, 1 fêmea (INPA); ibidem, 3.ix.1991, 1 fêmea (INPA); ibidem, 9.x.1991, 1 fêmea e 1 macho (INPA); ibidem, 12.xii.1991, 1 fêmea (INPA); ibidem, 14.xii.1991, 1 macho (INPA); ibidem, 6.ii.1992, 1 fêmea (INPA); ibidem, 10.ix.1990, C[ultura] [de] Guaraná, 1 fêmea e 1 macho (INPA); ibidem, 5.xii.1990, 1 fêmea (INPA); ibidem, 28.xii.1990, 1 macho (INPA); ibidem, 27.ii.1991, 1 fêmea (INPA); ibidem, 29.viii.1990, Capoeira, 1 fêmea (INPA); ibidem, 3.ix.1990, 1 fêmea (INPA); ibidem, 31.x.1990, 1 fêmea e 1 macho (INPA); ibidem, 5.xii.1990, 1 fêmea (INPA); ibidem, 26.xii.1990, 1 macho (INPA); ibidem, 24.v.1991, 1 macho (INPA); ibidem, 28.viii.1991, 1 fêmea (INPA); ibidem, 9.x.1991, 1 fêmea (INPA); ibidem, 13.xi.1991, 1 fêmea (INPA); Manaus, Campus Univ[ersitário], 19.iii.1979, J. A. Rafael leg., 1 macho (INPA); ibidem, 04.xi.1978, ar[madilha] Malaise, 1 fêmea (INPA); R[eserva] [Adolpho] Ducke, [26 km NE, $2^{\circ} 53^{\prime} \mathrm{S} 59^{\circ} 59^{\prime} \mathrm{W}$ ], 6.iii.2002, arm. McPhail, área aberta, platô, E. F. Soares \& A. L. Pinheiro leg., 1 macho (MCZ); ibidem, 10.ix.2002, 2 fêmea (INPA); ibidem, 6.viii.2002, baixio, 1 fêmea (INPA); ibidem, 6-16.ix.2002, 1 fêmea (INPA); ibidem, 613.ix.2002, mata, baixio, Ig[arapé] Barro Branco, 1 fêmea (INPA); ibidem, 10.ix.2002, mata, platô, 1 fêmea (INPA); ibidem, 24.xi08.xii.1988, isca de fruta, Y. Câmara \& J. F. Vidal leg., 1 fêmea (INPA); ibidem, 12-19.i.1989, 1 macho (INPA); ibidem, 16-23.ii.1989, Y. Câmara \& J. E. Bindá leg., 1 macho (INPA); ibidem, 21.xi.2001, arm. Shannon, palmeiras de buriti, J. F. Vidal leg., 2 fêmea (INPA); ibidem, 8.xi.1977, L. P. Albuquerque leg., 2 machos (INPA); ibidem, 2428.vii.2000, clareira, [armadilha Shannon], isca de fruta, R. Ale-Rocha, J. F. Vidal \& A. P. Marques leg., 1 fêmea (INPA); ibidem, 25-29.ix.2000, 1 macho (INPA); ibidem, 23-27.x.2000, 1 macho (INPA); ibidem, 21-25.v.2001, 1 fêmea (INPA); ibidem, 23-27.vii.2001, 2 fêmeas (INPA); ibidem, 19-23.iii.2001, mata, 1 fêmea (INPA); ibidem, 2125.v.2001, 1 fêmea (INPA); ibidem, 23-27.vii.2001, 2 fêmea (INPA); [Estação Experimental de Fruticultura Tropical], BR-174, km 40, Roçadão, 16.i.1997, [armadilha McPhail em] goiaba, Ronchi-Teles leg., 1 fêmea e 1 macho (INPA); Presidente Figueiredo, iv.2001, arm. McPhail, B. Ronchi-Teles leg., 2 fêmeas (INPA); ibidem, 2 fêmeas (MCZ); Rondônia, Nova Califórnia, Projeto Reca, 10.v.1997, Arm. McPhail, B. Ronchi-Teles leg., 5 fêmeas (INPA); Nova Mamoré, Parque

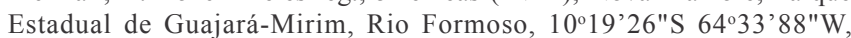
20-27.x.1995, arm. Malaise, [n ${ }^{\circ}$ ] 0018331, J. F. Vidal \& L. S. Aquino leg., 1 fêmea (INPA); Calama, 19-21.xi.1975, Exp. Perm. Amaz., 1 macho (MZSP); Forte Príncipe da Beira, 19.xi-03.xii.1967, G. R. Kloss leg., 1 fêmea (MZSP); Rio de Janeiro, Meyer, [?].1933, G. Fairchild, 1 macho (MCZ); Paraná, Paranaguá, iii.1937, G. Fairchild leg., 1 fêmea (MCZ); PERU, Loreto, $20 \mathrm{Km}$, Ucayali, R. Calleria, Colonia Calleria, 10.ix-30.ix.1961, B. Malkin leg., 1 fêmea (FMNH); ibidem, Madre de Dios, Manu, Rio Manu, $250 \mathrm{~m}$, Pakitza, $12^{\circ} 7^{\prime} \mathrm{S}, 70^{\circ}$ 58'W, 9-23.ix.1988, Amnon Freidberg leg., 2 fêmea (USNM); BOLÍVIA, [Santa Cruz], Prov[íncia] Sara, [sem data], Steinbach leg., 1 fêmea (INPA). Outros espécimes examinados. BELIZE, Toledo, Blue Creek Village, 07.vi.1981, Malaise trap, W. E. Steiner et. al. leg., 1 macho (INPA); HONDURAS, [Cortés], Tela, Lancetilla creek, 16.iii.1923, T. H. Hubbell leg., 1 macho (INPA); ibidem, Guaimas district, 03.v.1923, 1 fêmea (USNM); ibidem, 02.v.1923, 1 fêmea (USNM); Progreso, 25.iii.1923, T. H. Hubbell leg., 1 macho (USNM); Manatee, 4.i.1902, J. I. Neey leg., 1 macho (USNM); COSTA RICA, [Alajuela], Higuito San Mateo, [sem data], Pablo Schild leg., 1 fêmea e 1 macho (USNM) e 1 macho (INPA); PANAMÁ, C[anal] Z[one], Corozal, [sem data], J. Zetek leg., 1 macho (USNM) e 1 macho (INPA);
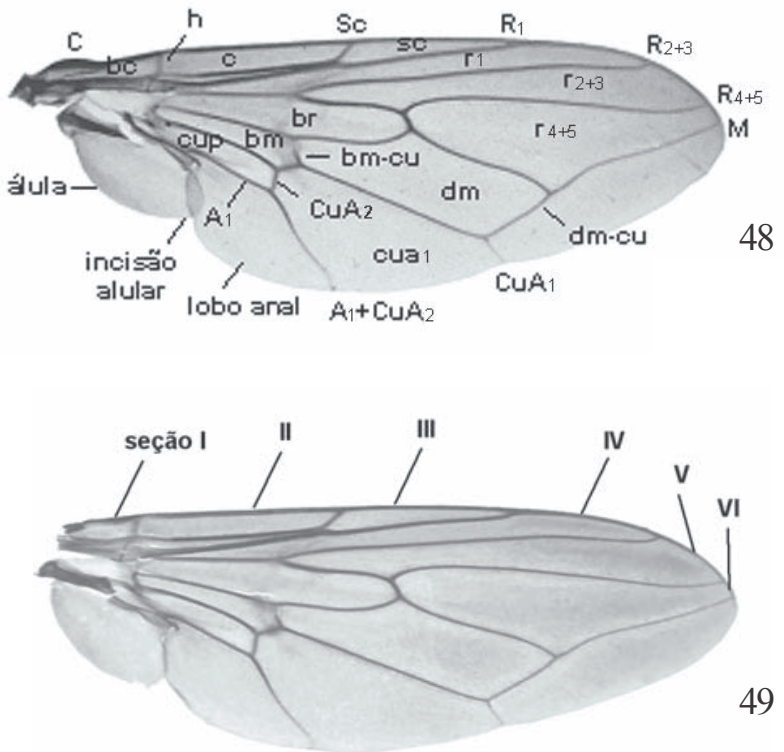

49
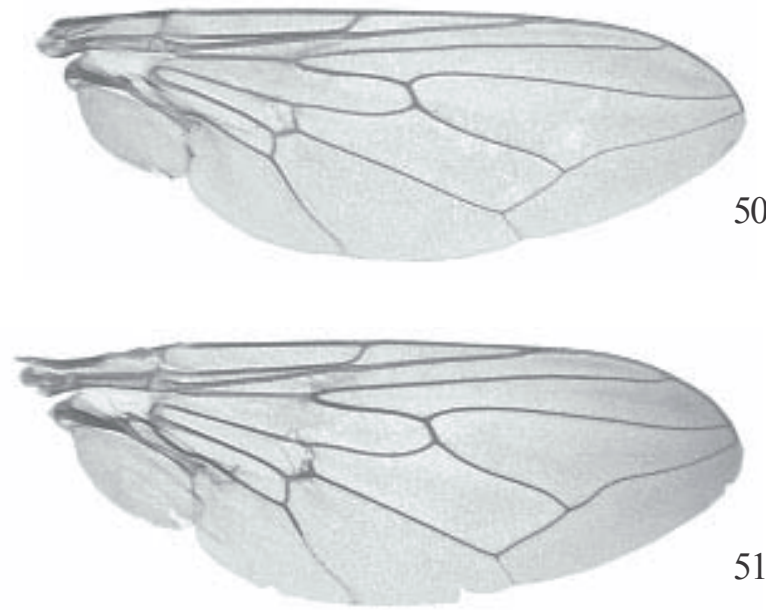

Figs. 48-51. Asas: 48, Willistoniella latiforceps sp. nov. (parátipo macho); 49, W. pleuropunctata (fêmea); 50 , W. spatulata sp. nov. (parátipo macho); 51, W. ulyssesi sp. nov. (parátipo macho).

ibidem, 02.viii.1922, "from trunk of cocoanut palm", 1 macho (USNM); VENEZUELA, T[erritorio] F[ederal] Amaz[onas], Cerro de la Neblina, Basecamp, 050’N 669'44", 140m, 13-20.ii.1984, D. Davis \& T. McCabe leg., 1 fêmea (INPA); ibidem, Zulia, Los Angeles del Tucuco, 15-16.iv.1981, E. E. Grissel leg., rain forest vegetation, 1 macho (INPA); ibidem, Valle Seco, Carabobo, i.[19]40, P. Anduze leg., 1 macho (USNM); TRINIDADE, Aripo Savana, 26.x.1918, A-841, Harold Morrison leg., 1 fêmea (INPA); BRASIL, [Roraima], Boa Vista, Mu[nicípio] Castanhal, 14.i.1965, H. Schubart leg., 1 fêmea (MPEG); Amapá, Serra do Navio, 02.x.1957, J. Lane leg., 1 fêmea (INPA); ibidem, 05.x.1957, 1 fêmea (MZSP); Pará, 09.ix.1982, em resina no tronco do taperebazeiro, I. S. Gorayeb leg., 2 machos (MPEG); Tucuruí, Rio Tocantins, Saúde, 01-03.vi.1984, armadilha suspensa, 2m, 1 fêmea (MPEG); ibidem, 03-05.vi.1984, armadilha Malaise, 1 fêmea (MPEG); ibidem, margem esquerda [do] Rio Arapari, 27.[?].1984, T. Pimentel leg., 1 macho (MPEG); Vigia, Campina, ilha de mata, 07.xii.1988, armadilha suspensa, 2m, W. França leg., 1 fêmea (MPEG); Paragominas, Faz. Cachoeira do Rio Vermelho, 15-18.i.1991, armadilha Malaise, J. 
Dias leg., 1 fêmea (MPEG); Marajó, Breves, R. Caruacá, 5.viii.1988, R. Santos leg., 1 macho (MPEG); ibidem, 12.viii.1988, J. Dias leg., 1 fêmea (MPEG); Ourém, Faz. Gavião Real, 27.x.1990, armadilha Malaise, P. Tadeu leg., 1 fêmea (MPEG); Benevides, Est. Neópolis, Sítio D. Doca, [?].vii.1991, W. Overal leg., 1 macho (MPEG); ibidem, 11.iv.1973, A. Souza leg., 1 fêmea (MPEG); Carajás, Est. Fofoca, 25.iv.1983, arm. suspensa, isca de fruta, Mascarenhas e equipe leg., 1 fêmea (MPEG); Gorotire, Xingu, 14.xi.1977, D. A. Posey leg., 1 fêmea (MPEG); Amazonas, Manaus, ix.1962, K. Lenko leg., 1 fêmea e 1 macho (MZSP); ibidem, $1 \mathrm{Km}$ W “Tarumã Falls", 02.iii.1981, 100m, C. Young leg., 1 fêmea (MPEG); Puruzinho, Rio Madeira, 14-17.xi/ 36.xii.1975, Exp. Perm Amaz., 1 fêmea (MZSP); Tapurucuara, Rio Negro, 22.ii.1962, J. \& B. Bechyné leg., 1 fêmea (MPEG); Acre, Porto Acre, Humaitá, 15.vi a 02.vii.[19]92, armadilha suspensa, $11.6 \mathrm{~m}$, Gorayeb, Pena Henriques Edmar leg., 1 fêmea (MPEG); Rondônia, Ouro Preto do Oeste, linha 212, lote 36, gleba 21-B, 02.ix.1986, F. F. Ramos leg., 1 fêmea (MPEG); Ji-Paraná, 17-20.xi.1984, armadilha suspensa, 16m, 1 macho (MPEG); Goiás, Jataí, i.1955, M. Carrera, A. Machado, F. S. Pereira, E. Dente \& Milgar Loureiro leg., 1 fêmea (INPA); E[spírito] S[anto], Itaguaçu, x.1970, P. C. Elias leg., 1 fêmea (MZSP); ibidem, Conceição da Barra, iv.[19]72, 1 fêmea (MZSP); Rio de Janeiro, viii.1938, Serviço Febre Amarela M. E. S., Bras., [coletor anônimo], 2 fêmeas e 7 machos (USNM); ibidem, ix.1938, 10 fêmeas e 12 machos (USNM); ibidem, Yel[low] Fev[er] Srv[ice], M. E. S. Brazil, R. C. Shannon leg., 3 fêmeas e 6 machos (USNM); ibidem, x.1938, 5 fêmeas e 11 machos (USNM); ibidem, i.1939, 1 fêmea (USNM); ibidem, ii.1939, 1 fêmea e 2 machos (INPA); ibidem, iii.1939, 1 fêmea e 1 macho (INPA); ibidem, ix.1938, R. C. Shannon leg., 1 fêmea e 2 machos (USNM); ibidem, i.[19]39, 3 machos e 3 fêmeas (USNM); ibidem, Mangaritiba, viii.[19]38-ii.[19]39, R. C. Shannon leg., 12 machos (USNM); ibidem, Xerém, vii.[19]69, H. Ebert leg., 1 fêmea (MZSP); EQUADOR, Napo, Lago Agrio, 8 Km W, 28.viii.1975, "Malaise trap", Langley \& Cohen leg., 1 fêmea (INPA); ibidem, Province, Tena, 23.v.1977, D. L. \& S. S. Vincent leg., 1 fêmea (USNM); PERU, S. E. Cusco, Avispas, ix.1962, L. E. Peña leg., 1 fêmea e 1 macho (MZSP); [Loreto], Iquitos, iii-iv.1931, R. C. Shannon leg., 2 fêmeas e 1 macho (USNM) e 1 fêmea (INPA); BOLÍVIA, Beni, Rurrenabaque, 22.x.1921, Mulford Bio. Expl., W. M. Mann leg., 1 macho (INPA); ibidem, nr. mouth, Rio Mapiri, 22.ix.1921, 1 fêmea (USNM); PARAGUAI, [Guairá], Villarica, ii.1939, F. Schade leg., 1 macho (USNM).

Variações. Fronte inteiramente castanha; 7-9 cerdas pósoculares presentes; coloração da face muito variável, a maioria dos exemplares como no holótipo, podendo ainda a faixa da carena ser descontínua ou mais larga; um número menor de exemplares apresentou a face com coloração inteiramente amarelada ou castanha, sem manchas distintas; artículos antenais ferrugíneos a castanhos; flagelo mais escuro na margem dorsal; faixa acrostical de polinosidade prateada do escuto ausente; 6-9 cerdas no esclerito parafacial; número de cerdas das pernas variável, mas sempre com o mesmo padrão de distribuição; um exemplar fêmea apresentou 1 cerda dorsocentral extranumerária no lado direito do corpo; expansão lateral membranosa do parâmero com uma pequena reentrância no ápice, característica observada em poucos exemplares.

Comentários. Esta espécie confunde-se algumas vezes com $W$. pleuropunctata e $W$. spatulata $\mathbf{s p . ~ n o v . , ~ n o ~ q u e ~ d i z ~ r e s p e i t o ~}$ à coloração da face. Nos casos em que a mancha da carena $\mathrm{e}$ das laterais da face é bem definida, pode ser facilmente separada. Entretanto, às vezes a mancha da carena é mais larga, similar a de $W$. spatulata sp. nov. Existem ainda, exemplares com a face inteiramente amarelada ou castanha, sem manchas distintas, semelhantes à W. pleuropunctata, embora estes sejam em número menor (geralmente fêmeas). Para uma separação mais segura da espécie, é necessário recorrer à morfologia da terminália. $\mathrm{O}$ macho distingue-se por possuir o surstilo mais longo que o de $W$. pleuropunctata, ultrapassando a margem posterior do epândrio; no aspecto geral, a terminália é maior do que em $W$. pleuropunctata, e o epândrio tem formato distinto; o epifalo e parâmero são muito semelhantes aos de $W$. pleuropunctata, porém um pouco mais engrossados. $W$. ulyssesi sp. nov. é a única espécie do gênero na qual a fêmea possui ondulações no esternito 7 , sendo por isso, facilmente separada das demais fêmeas.

Etimologia. O nome ulyssesi é uma homenagem ao técnico Ulysses C. Barbosa, que coletou um casal em cópula, permitindo assim, que fosse feita a correta associação entre macho e fêmea.

Agradecimentos. Ao Dr. José Albertino Rafael/ Dr. Augusto L. Henriques (INPA), Dr. Orlando Tobias Silveira/ Dra. Ana Yoshi Harada (MPEG), Dra. Sônia Casari (MZSP), Dra. Ruth Contreras-Lichtenberg/ Dr. Peter Sehnal (NHMW), Dr. Philip Parrillo (FMNH), Dr. Philip D. Perkins (MCZ) e Dr. Allen L. Norrbom (USNM) pelo empréstimo dos espécimes, e à Coordenação de Aperfeiçoamento de Pessoal de Nível Superior (CAPES) pela bolsa de mestrado concedida à primeira autora.

\section{REFERÊNCIAS}

Aldrich, J. M. 1905. A Catalogue of North American Diptera. Smithsonian Institution Miscellaneous Collections 46: 1680 .

Aldrich, J. M. 1932. New Diptera, or two-winged flies from America, Asia, and Java, with additional notes. Proceedings of the United States National Museum 81: 1-28.

Baez, M. 1985. Los Ropaloméridos de Venezuela (Diptera: Ropalomeridae). Boletín de Entomologia Venezolana 4: 77 81.

Fischer, C. R. 1932. Um gênero e duas espécies novas de Rhopalomeridae do Brasil, e o pupário de Willistoniella pleuropunctata Wied. (Dipt.). Revista de Entomologia 2: 441-450.

Frey, R. 1921. Studien über den Bau des Mundes der niederen Diptera Schizophora nebst Bemerkungen über die Systematik dieser Dipteren-gruppe. Acta Societatis Fauna Flora Fennica 48: 1247.

Frey, R. 1959. Üeber südamerikanische Rhopalomeriden (Diptera). Notulae Entomologicae 39: 47-48.

Giglio-Tos, E. 1894. Diagnosi di nuovi generi e di nuovi specie di ditteri. Bolletino del Museo Regionale di Scienze Naturali di Torino 8: 1-14.

Hendel, F. 1923. Die palaarktischen Muscidae acalyptratae Girschn. = Haplostomata Frey nach ihren Familien und Gattungen. II. Die gattungen. Konowia 2: 203-215.

Hendel, F. 1933. Von Dr. Zürcher in den Jahren 1913-1918 in Paraguay gesammelte acalyptrate Dipteren. Revista de Entomologia 3: 213-224.

Hennig, W. 1958. Die Familien der Diptera Schizophora und ihre phylogenetischen Verwandtschftsbeziehungen. Beiträge zur Entomologie 8: 505-688.

Lindner, E. 1930a. Revision der amerikanischen Dipteren-Familie der Rhopalomeridae. Deutsche Entomologische Zeitschrif 2: 122137.

Lindner, E. 1930b. Die Ausbeute der Chaco-Expedition 1925/26 Diptera. Konowia 9: 281-284. 
Malloch, J. R. 1941. Florida Diptera. Family Rhopalomeridae. Florida Entomologist 24: 49-51.

McAlpine, J. F. 1981. Morphology and terminology - Adults, p. 9-63. In: J. F. McAlpine (coord.). Manual of Nearctic Diptera. Vol. 1. Res. Branch Agr. Canada Monogr. 27.

Mik, J. 1895. Bemerkungen zu den Dipteren - Gattungen Pelecocera Meig. Und Rhopalomera Wied. Wiener Entomologische Zeitung 14: 133-136.

Papavero, N. 1971. Essays on the history of Neotropical Dipterology. Vol. I, São Paulo, Museu de Zoologia da Universidade de São Paulo, 216 p.

Prado, A. P. 1963. Primeira contribuição ao conhecimento da família Rhopalomeridae (Diptera). Memórias do Instituto Oswaldo Cruz 61: 459-470.

Prado, A. P. 1966. Segunda contribuição ao conhecimento da família Rhopalomeridae (Diptera, Acalyptratae). Studia Entomologica 8 [1965]: 209-268.

Prado, A. P. 1967. Sobre alguns Ropalomeridae do American Museum of Natural History, New York (Diptera, Acalyptratae). Revista Brasileira de Biologia 27: 71-75.

Prado, A. P. \& N. Papavero. 2002. Insecta - Diptera - Ropalomeridae, p. 1-3. In: N. Papavero (ed.). Fauna da Amazônia Brasileira. Vol. 5. Belém, Museu Paraense Emílio Goeldi.

Ramírez-García, E. \& V. Hernández-Ortiz. 1994. Revisión de la familia Ropalomeridae (Diptera) en Mexico. Acta Zoologica Mexicana 61: $57-85$.
Rondani, G. 1848. Esame di varie specie d'insetti ditteri brasiliani. In: Truqui, Studia Entomologica 1: $63-112,3$ pl.

Rübsaamen, E. H. 1892. Die Gallmücken des Königl. Museums für Naturkunde zu Berlin. Berliner Entomologische Zeitschrift 37: 319-411.

Steyskal, G. C. 1957. The postabdomen of male Acalyptrate Diptera. Annals of the Entomological Society of America 50: 66-73.

Steyskal, G. C. 1967. Family Ropalomeridae, p. 1-7. In: A catalogue of the Diptera of the Americas South of the United States. São Paulo, Departamento de Zoologia, Secretaria de Agricultura, v. 60 .

Steyskal, G. C. 1987. Ropalomeridae, p. 941-944. In: J. F. McAlpine (ed.). Manual of Nearctic Diptera. Vol. 2. Res. Branch Agr. Canada Monogr. 28.

Walker, F. 1858. Characters of undescribed Diptera in the collection of W. W. Sauders. Transactions of the Entomological Society of London 4: 190-235.

Wiedemann, C. R. W. 1824. Munus rectoris in Academia Christiana Albertina aditurus. Analecta entomologica ex Museo Regio Havniensi, 60 pp., 1 pl. Kiliae (= Kiel).

Wiedemann, C. R. W. 1828. Aussereuropäische zweiflügelige Insekten 2: xii +684 pp., pls. 7-10b.

Williston, S. W. 1895. On the Rhopalomeridae. Psyche 7: 183-187.

Williston, S. W. 1896. Manual of the families and genera of North American Diptera. 2nd. ed., New Haven, J. T. Hathaway, 167 pp.

Recebido em 23.IX.2004; aceito em 29.III.2005 